\title{
Microbial Dynamics between Yeasts and Acetic Acid Bacteria in Kombucha: Impacts on the Chemical Composition of the Beverage
}

\author{
Thierry Tran ${ }^{1, *(1)}$, Cosette Grandvalet ${ }^{1}$, François Verdier ${ }^{2}$, Antoine Martin ${ }^{2}$, Hervé Alexandre ${ }^{1}$ \\ and Raphaëlle Tourdot-Maréchal ${ }^{1}$ \\ 1 UMR Procédés Alimentaires et Microbiologiques, Université de Bourgogne Franche-Comté/AgroSup Dijon, \\ Equipe Vin Alimentation Micro-organismes Stress (VAlMiS) Institut Universitaire de la Vigne et du Vin Jules \\ Guyot, 2 rue Claude Ladrey, BP 27877, 21000/26, bd Docteur Petitjean, BP 87999, 21079 Dijon, France; \\ cosette.grandvalet@u-bourgogne.fr (C.G.); rvalex@u-bourgogne.fr (H.A.); tourdot@u-bourgogne.fr (R.T.-M.) \\ 2 Biomère, 14 rue Audubon, 75120 Paris, France; fverdier@jubiles.bio (F.V.); amartin@jubiles.bio (A.M.) \\ * Correspondence: thierrytran01@gmail.com
}

Received: 24 June 2020; Accepted: 20 July 2020; Published: 21 July 2020

check for updates

\begin{abstract}
Kombucha is a traditional low-alcoholic beverage made from sugared tea and transformed by a complex microbial consortium including yeasts and acetic acid bacteria (AAB). To study the microbial interactions and their impact on the chemical composition of the beverage, an experimental design with nine couples associating one yeast strain and one AAB strain isolated from original black tea kombucha was set up. Three yeast strains belonging to the genera Brettanomyces, Hanseniaspora, and Saccharomyces and three strains of Acetobacter and Komagataeibacter species were chosen. Monocultures in sugared tea were analyzed to determine their individual microbial behaviors. Then, cultivation of the original kombucha consortium and cocultures in sugared tea were compared to determine the interactive microbial effects during successive phases in open and closed incubation conditions. The results highlight the main impact of yeast metabolism on the product's chemical composition and the secondary impact of bacterial species on the composition in organic acids. The uncovered microbial interactions can be explained by different strategies for the utilization of sucrose. Yeasts and AAB unable to perform efficient sucrose hydrolysis rely on yeasts with high invertase activity to access released monosaccharides. Moreover, the presence of AAB rerouted the metabolism of Saccharomyces cerevisiae towards higher invertase and fermentative activities.
\end{abstract}

Keywords: kombucha; yeasts; acetic acid bacteria; interactions; symbiosis; sucrose hydrolysis; pellicle

\section{Introduction}

Fermented food is often designated as a convenient model for the study of microbial communities and interactions [1-3]. Kombucha is an increasingly exploited example of a fermented beverage obtained by microbial communities. Kombucha, also named "kombucha tea", results from the metabolic interplay of a microbial consortium including acetic acid bacteria (AAB), yeasts, and often (but not always) lactic acid bacteria in sugared tea liquor [4-6]. Infusion provides nitrogenous substances extracted from tea necessary for the growth of microorganisms. Sucrose is converted into glucose and fructose by periplasmic yeast invertase and ethanol is produced as a result of alcoholic fermentation. $\mathrm{AAB}$ oxidize glucose into gluconic acid and ethanol into acetic acid through oxidative metabolism. This metabolic scheme raises the question of a possible trophic dependency of AAB towards yeasts [7]. Glucose and fructose are also used for bacterial cellulose production, leading to the formation of the pellicle, also known as "mother", "tea fungus", or Symbiotic Culture of Yeast and Bacteria ("SCOBY"), since it can be used as inoculum with or instead of liquid culture $[4,5,8]$. As a result, the beverage has 
the profile of a soda with a sweet/sour balance and can also be carbonated naturally if the vessel is left closed after a first phase of biological acidification at ambient temperature [9]. There is no single "culture" or microbial consortium for the production of kombucha, but a multitude of matrix-adapted consortia whose origins are unknown. This matrix also offers two distinct environments: A liquid phase, where microorganisms are in a planktonic state, and a pellicle, where they are entrapped. Biofilms are known to host numerous interaction mechanisms among microbial communities and the cellulosic pellicle produced by the AAB of kombucha is no exception [10-12]. Beyond this trophic interaction, little is known about other types of interactions that might occur during kombucha fermentation at genus or species levels. The formation of the pellicle, as well as the drop of $\mathrm{pH}$, can work as protection against contamination by exogenous spoilage agents such as molds [13]. Inside the consortium, inter-kingdom and intra-kingdom interaction mechanisms remain poorly documented.

Some studies have provided clues on the existence of interactions through the lens of microbial dynamics. The results have shown that some bacterial species are dominant, but the dynamics are dependent on the type of tea used (black or green) [14]. It has also been shown that the population of some yeast species decreases during kombucha fermentation, while others remain stable, as was the case for Torulaspora delbrueckii or Schizosaccharomyces pombe in the presence of Zygosaccharomyces bailii. In this case, the impacted yeast species were dependent on the consortium and this phenomenon did not occur in pellicles, with all populations being maintained [15]. Microbial interaction data based on indigenous complex consortia are difficult to summarize because of the complexity of the original system. Focus has been placed on microbial dynamics in terms of populations, without investigating the impact on the chemical composition of the beverage. To the best of our knowledge, only one study has investigated the interactions between individual isolates from kombucha by cultivating AAB (Acetobacter sp.) in sugared black tea with the addition of autoclaved sugared black tea fermented by a single strain of yeast (Saccharomyces cerevisiae, Brettanomyces bruxellensis, and Zygosaccharomyces bailii) [16]. This study concluded on the positive impact of the addition of fermented medium on AAB growth and also suggested that acetic acid produced by $\mathrm{AAB}$ could stimulate the production of ethanol by yeast. A recent study compared an original kombucha consortium with an unknown microbial composition, and a synthetic consortium including purchased isolates of species commonly found in kombucha [17]. Two AAB species, consisting of Acetobacter pasteurianus and Komagataeibacter xylinus, were used with the yeast species $Z$. bailii. The study confirmed the technical suitability of using a synthetic consortium of yeasts and $\mathrm{AAB}$ for the fermentation of kombucha beverages and highlighted the metabolic interplay between yeasts and AAB.

The present study goes further in the study of the yeast-bacterium interaction that occurs during kombucha fermentation in terms of both microbiological levels and the composition of the main metabolites produced. Yeasts and bacterial strains were isolated from an original black tea kombucha culture, identified, and selected to develop an experimental design with three yeast strains and three $\mathrm{AAB}$ strains. Each yeast and $\mathrm{AAB}$ was characterized individually, co-inoculated (one yeast strain $\mathrm{x}$ one AAB strain, with " $x$ " indicating a coculture) in sugared black tea, and compared to the original consortium. This methodology was inspired by the integrated design for the study of microbial communities described by Lawson et al. (2020), consisting of joint studies of the original consortium, with simplified and deconstructed consortia reassembled using isolates [18]. Moreover, on top of the aerobic acidification phase, the anaerobic carbonation phase in a closed bottle was investigated for the first time.

\section{Materials and Methods}

A diagram summing up the experiment is available as Supplementary Data (Figure S1).

\subsection{Isolation and Identification of Microbial Species}

Yeast and bacterial strains were isolated from liquid and pellicle samples of black tea kombucha from the company Biomère (Paris, France). WallersteinLab (WL) agar medium from Thermo Fisher 
Scientific (Waltham, MA, USA) was used to isolate yeasts [19]. Bromocresol Green allowed a macroscopic discrimination of colonies based on their aspect and color for the set of yeasts isolated in the present study [20,21]. De Man Rogosa and Sharpe (MRS) ( $\mathrm{pH}$ 6.2) from Condalab (Madrid, Spain), LAC ( $\mathrm{pH}$ 5.1), and Mannitol agar media [22] were used for the isolation of bacteria that may have different nutritional requirements in both aerobic and anaerobic conditions of incubation [23]. All reagents used in agar media were purchased from Merck (Darmstadt, Germany), if not otherwise specified.

Five yeast colonies per colony morphotype were separately picked-up for inoculation in Yeast Peptone Dextrose (YPD) liquid medium $\left(48 \mathrm{~h}\right.$ at $\left.28^{\circ} \mathrm{C}\right)$. Twenty-five bacterial colonies per agar medium were separately picked-up for inoculation in LAC medium $\left(48 \mathrm{~h}\right.$ at $28^{\circ} \mathrm{C}$ in the aerobic condition of incubation), since all species identified on Mannitol agar medium were also identified on LAC agar medium. After incubation, culture media were eliminated by centrifugation $\left(14.500 \times g, 3 \mathrm{~min}\right.$ at $\left.15^{\circ} \mathrm{C}\right)$. A half volume of appropriate liquid medium with a half volume of $40 \%(\mathrm{v} / \mathrm{v})$ glycerol was then added to the samples to make a stock kept at $-20^{\circ} \mathrm{C}$.

DNA extraction from each isolated strain was performed using an Instagen Matrix kit (Bio-Rad, Hercules, CA USA). For yeasts, the $26 \mathrm{~S}$ rDNA region ribosomal non transcribed spacer 2 (NTS 2) was amplified using the following primers: NL1 (5'-GCATATCAATAAGCGGAGGAAAAG- $3^{\prime}$ ) and NL4 (5'-GTCCGTGTTTCAAGACGG-3') [24]. Two microliters of extracted DNA were added to $25 \mu \mathrm{L}$ PCR mix (1.8 $\mathrm{mM} \mathrm{MgCl}_{2}, 0.25 \mathrm{mM}$ dNTPs, $1.25 \mu \mathrm{M}$ of each primer, and $0.025 \mathrm{U}$ Taq polymerase) (Promega Corp., Madison, WI, USA). A Biorad (Hercules, CA, USA) thermocycler was used as described previously [25].

For bacteria, 16S ribosomal DNA was amplified using the following primers: E517F (5'-GCCAGCAGCCGCGGTAA-3') and E106R (5'-CTCACGRCACGAGCTGACG-3'). Amplification was performed in the same conditions as for the yeasts, except for the annealing temperature, which was changed to $58{ }^{\circ} \mathrm{C}$ [26]. Both strands Sanger sequencing was performed on amplified DNA by Genewiz ${ }^{\circledR}$ (Leipzig, Allemagne) using NL1 and NL4 primers for yeasts and E515F and E106R primers for bacteria. The sequences obtained were then analyzed using the software Geneious R7 (version 7.1.5) and the Basic Local Alignment Search Tool (BLAST) available on NCBI's website (https://blast.ncbi.nlm.nih.gov/Blast.cgi), thus returning genus and species names.

\subsection{Growth Conditions}

In order to generate pure precultures, yeasts were restreaked on WL agar and bacteria were restreaked on MRS agar from stocks kept at $-20^{\circ} \mathrm{C}$ and incubated at $28^{\circ} \mathrm{C}$. MRS agar was chosen because it is a commonly used growth medium for exigent bacteria, and the growth of each isolated $\mathrm{AAB}$ species on this medium was tested prior to the experiment.

Cultivation of the original kombucha consortium and cocultures was initiated in sugared tea. To produce $1 \mathrm{~L}$ of sugared black tea, tap water was filtered through a Brita (Taunusstein, Allemagne) charcoal cartridge and sterile filtered by a Steritop ${ }^{\circledR}$ cartridge by Merck (Darmstadt, Allemagne). Then, $200 \mathrm{~mL}$ of sterile tap water was boiled and directly taken off the heating source. One gram of black tea (Pu'er Grade 1 TN4107 from "Les jardins de Gaïa") (Wittisheim, France) was immediately added and left for infusion for one hour at room temperature. Tea was then removed using a sieve and transferred to a sterile vessel. A total of $800 \mathrm{~mL}$ of sterile tap water at $26^{\circ} \mathrm{C}$ was added. Then, $60 \mathrm{~g}$ sucrose was added and dissolved completely. The mix was kept at $26^{\circ} \mathrm{C}$ in a closed Schott ${ }^{\circledR}$ flask for one hour, prior to inoculation. Yeast and AAB strains were cultivated in YPD and MRS liquid medium, respectively. The tubes were not fully closed, in order to allow gaseous exchange during the incubation at $28^{\circ} \mathrm{C}$ in static conditions for 3 days. Before inoculation in sugared tea, cells from pure cultures were washed with sugared black tea and then centrifugated $\left(3.000 \times g ; 10 \mathrm{~min}\right.$ at $\left.4{ }^{\circ} \mathrm{C}\right)$. The populations of pure cultures were determined using a BD Accuri C6 (Franklin Lakes, NJ, USA) flow cytometer coupled with $0.1 \mu \mathrm{g} \mathrm{mL}^{-1}$ propidium iodide marking for cell mortality [27].

The choice of the target inoculation rate for individual species was based on the population levels determined for original kombucha at the inoculation time. Consequently, sugared black tea 
was then inoculated using precultures with an initial population of yeast or AAB of $1.10^{5}$ cells $\mathrm{mL}^{-1}$. For cocultures, the same process as that employed for pure cultures was used, with initial populations of $1.10^{5}$ cells $\mathrm{mL}^{-1}$ for both yeast and bacterium strains.

The production of kombucha was carried out using a kombucha mother culture maintained in the lab from the original black tea kombucha sample from Biomère (Paris, France) by adding a half volume of sugared black tea each month. Kombucha mother culture was added to sugared black tea at the rate of $12 \%(\mathrm{v} / \mathrm{v})$ and kept at $26^{\circ} \mathrm{C}$ for 14 days in a $500 \mathrm{~mL} \mathrm{Schott}{ }^{\circledR}$ bottle, in order to produce a fresh kombucha inoculum. $12 \%$ of this inoculum was added to fresh sugared black tea to produce the traditional kombucha used in this study.

Monocultures, cocultures, and original kombucha incubations were performed in $125 \mathrm{~mL}$ Boston flasks with a Specific Interfacial Surface (SIS) of $0.01 \mathrm{~cm}^{-1}$ in a final volume of $123 \mathrm{~mL}$ [28]. For monocultures in an open incubation condition (IC), bottlenecks were loosely covered with tin foil to allow gas exchange, whereas for closed IC, flasks were closed using a cap to reflect bottling. Monocultures were characterized in both open and closed IC at $26^{\circ} \mathrm{C}$ after 7 and 14 days for microbiological analysis and after 14 days for chemical analyses. Cocultures and kombucha incubations were carried out in two phases. The first phase (P1) of fermentation was performed for 14 days at $26^{\circ} \mathrm{C}$ in the same open IC as monocultures. Then, half of the volume was withdrawn for analysis ("P1" samples). The bottles were then sealed, in order to trigger natural carbonation. This phase (P2) was performed at $26^{\circ} \mathrm{C}$ for 10 days. At the end, the samples were analyzed ("P2" samples). Open and closed IC do not strictly reflect aerobic or anaerobic systems, but rather the production process of kombucha making in industrial conditions. Dissolved oxygen concentrations were not measured in samples. A description of the research samples and abbreviations is detailed as Supplementary Data (Table S2).

The populations of yeasts and/or bacteria during fermentation were determined by plating successive decimal dilutions of samples on WL agar for yeasts and MRS agar for bacteria, with technical triplicates for each biological triplicate.

\subsection{Chemical Analyses}

For chemical analyses, samples were kept frozen at $-20{ }^{\circ} \mathrm{C}$ and centrifuged prior to chemical analyses $\left(3.000 \times \mathrm{g} ; 15 \mathrm{~min}, 10^{\circ} \mathrm{C}\right)$. $\mathrm{pH}$ values were measured with a Mettler Toledo Five Easy $\mathrm{pH}$ meter coupled with an LE498 probe. The total acidity was determined by titration with $0.1 \mathrm{~N} \mathrm{NaOH}$ and $0.2 \%$ phenolphthalein as a color indicator [29].

Acetic, lactic, malic, and succinic acid concentrations were determined by HPLC with a VWR Hitachi (Tokyo, Japan) control unit, L-2350 oven, L-2200 autosampler injection device, and L-2130 pump. The column used was a Raptor ARC-18 $2.7 \mu \mathrm{m} 150 \times 2.1 \mathrm{~mm}$ from RESTEK (Lisses, France) and the detector was a UV Diode Array Detector VWR Hitachi L-2455 (Tokyo, Japan) at $210 \mathrm{~nm}$. The mobile phase was $97 \% 20 \mathrm{mM} \mathrm{KH}_{2} \mathrm{PO}_{4}$ (pH 2.4) and $3 \%$ methanol. A flow gradient was applied at $35^{\circ} \mathrm{C}$, with the following sequence for a total duration time of $10 \mathrm{~min}$ : From $0.1 \mathrm{~mL} \mathrm{~min}^{-1}$ to $1.0 \mathrm{~mL} \mathrm{~min}^{-1}$ for

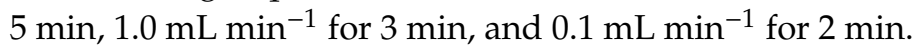

Sucrose, glucose, and fructose concentration determinations by HPLC involved the same equipment, except for the column. A HyperREZ XP Carbohydrate Ca++ $8 \%$ column from Thermofisher (Waltham, Etats-Unis) was used with a Spectrasystem RI-150 refractometer from de JMBS (Mandelieu-Napoule, France). The flow rate was $0.6 \mathrm{~mL} \mathrm{~min}{ }^{-1}$ with ultrapure water at $80^{\circ} \mathrm{C}$.

Gluconic acid and ethanol concentrations were determined using enzymatic kits from Biosentec (Auzeville-Tolosane, France).

The free amino nitrogen (FAN) concentration was determined according to the protocol from $\operatorname{MEBAK}^{\circledR}$ (2013) [30], with the following adaptation. In total, $0.4 \mathrm{~mL}$ 20-fold diluted sample was added to $0.2 \mathrm{~mL}$ reactive mix $\left(0.71 \mathrm{M} \mathrm{Na}_{2} \mathrm{HPO}_{4}, 0.44 \mathrm{M} \mathrm{KH}_{2} \mathrm{PO}_{4}, 28 \mathrm{mM}\right.$ ninhydrin, and $17 \mathrm{mM}$ fructose). The mix was heated for $16 \mathrm{~min}$ at $100^{\circ} \mathrm{C}$ and left to cool down for $20 \mathrm{~min}$ at room temperature. Then, $0.8 \mathrm{~mL}$ dilution solution $(40 \%(\mathrm{v} / \mathrm{v})$ ethanol, $12 \mathrm{mM}$ potassium iodide) was added before the absorbance 
reading at $570 \mathrm{~nm}$ using a UV-1800 spectrophotometer from Shimadzu (Kyoto, Japan). Distilled water was used as the blank. A calibration curve was made using a glycine solution.

Analytical chemistry results were expressed as the balance, according to the following formula (1):

$$
\Delta \text { Concentration }=\Delta \text { Endpoint concentration }-\Delta \text { Initial concentration } \text {. }
$$

Initial corresponds to day 0 and the "endpoint" corresponds to day 14 for monocultures and "P1" or "P2" for cocultures.

\subsection{Statistical Analyses}

All samples were made in triplicate. Values were treated with ANOVA and in the case of significant differences $(p<0.05)$, the Newman-Keuls pair test was applied. Principal Component Analysis (PCA) coupled with Hierarchic Ascending Classification (HCA) was also performed for P1 and P2 values separately. All statistical analyses were performed with $\mathrm{R}$ software (version 3.5.2.).

\section{Results and Discussion}

\subsection{Isolation and Identification of Yeast and Bacterial Strains}

Based on the colony morphology on WL agar, yeast species in the original black tea kombucha sample were isolated and then identified by DNA sequencing of the 26S ribosomal region [24]. In the liquid phase, Brettanomyces (Dekkera) bruxellensis (small white colonies), Hanseniaspora valbyensis (dark green colonies), and Saccharomyces cerevisiae (large white colonies) were identified. In the biofilm, the same species were isolated, in addition to Hanseniaspora opuntiae (bright green colonies), Pichia aff. fermentans (white star-shaped colonies), and Galactomyces geotrichum (white filaments). Yeast colony morphologies were all distinct for each species. On agar plates, all AAB colonies had a sticky and translucid aspect. DNA sequencing of the $16 \mathrm{~S}$ ribosomal region [26] allowed the identification of the species Acetobacter indonesiensis, Acetobacter papayae, and Komagataeibacter saccharivorans, which were all isolated in both liquid and biofilm phases. All species names were associated with E-values equal to 0 . No lactic acid bacteria were identified, despite the use of LAC medium in both aerobic and anaerobic conditions of incubation. Except for Galactomyces geotrichum, the genera of isolated yeasts and bacteria are commonly found in kombucha [4]. For this study, species found in the liquid phase were chosen because they were present in both liquid and biofilm. Each of the selected strains was characterized in sugared black tea.

\subsection{Characterization of Pure Cultures in Sugared Black Tea}

Figure 1 presents the population levels of each selected strain inoculated in sugared black tea after inoculation on day 0 and after incubation for 7 days and 14 days at $26{ }^{\circ} \mathrm{C}$ in open and closed incubation conditions (IC). 


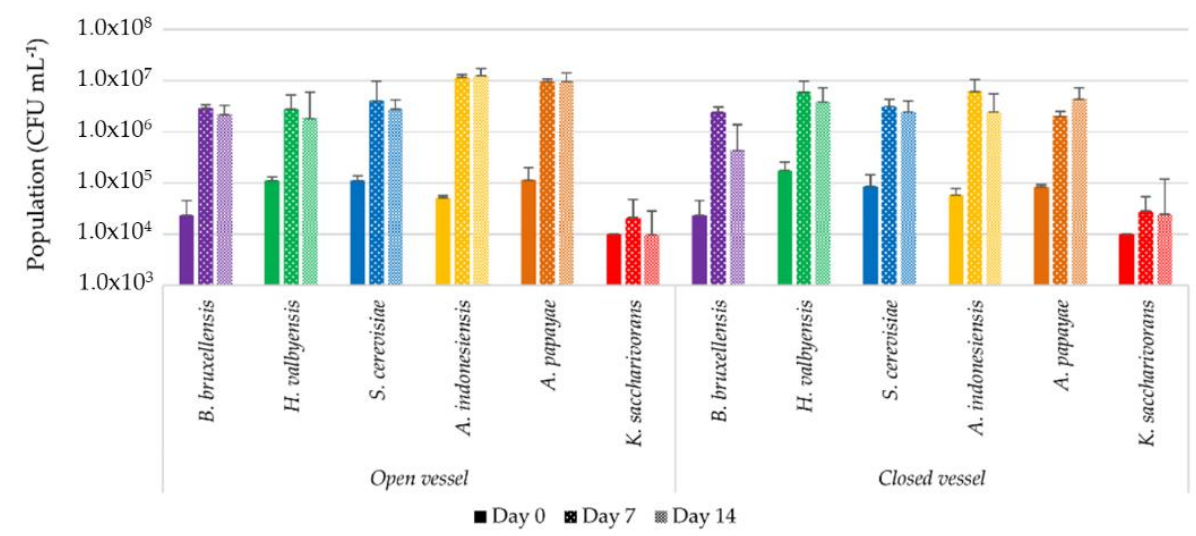

Figure 1. Microbial populations during cultivation in sugared black tea of a monoculture of yeast and bacterial strains isolated from black tea kombucha determined by plate counting $\left(\mathrm{CFU} \mathrm{mL} \mathrm{mL}^{-1}\right)$. Error bars correspond to the confidence interval with $\alpha=0.05(n=3)$. Cultures were conducted in open vessel (left) or closed (right) conditions of incubation for 14 days.

Yeast population levels increased from $1.0 .10^{5} \pm 5.10^{4} \mathrm{CFU} \mathrm{mL} \mathrm{m}^{-1}$ to values between $1.0 .10^{6} \mathrm{CFU}$ $\mathrm{mL}^{-1}$ and $6.0 .10^{6} \mathrm{CFU} \mathrm{mL}{ }^{-1}$, regardless of the open or closed IC after 7 days. These levels of population were maintained 7 days later.

Except for K. saccharivorans, $\mathrm{AAB}^{\prime}$ s population levels increased from $1.0 .10^{5} \pm 5.10^{4} \mathrm{CFU} \mathrm{mL}^{-1}$ to values between 1.0.106 $\mathrm{CFU} \mathrm{mL} \mathrm{m}^{-1}$ and $1.0 .10^{7} \mathrm{CFU} \mathrm{mL}{ }^{-1}$, regardless of the open or closed IC after 7 days. It can be supposed that, on top of assimilable nutrients, the medium initially possessed a sufficient dissolved oxygen level to allow the growth of AAB in closed IC. These levels of population were maintained 7 days later. K. saccharivorans possessed a lower population at day 0 and the population only increased by less than $1 \log$. Discrepancies between the target inoculation rate and plate counting results at day 0 could be due to the viable but not culturable (VBNC) state, as reported for Komagataeibacter xylinus [31,32].

The average initial composition of sugared black tea was $66.6 \pm 3.3 \mathrm{~g} \mathrm{~L}^{-1}$ total sugars $\left(66.4 \mathrm{~g} \mathrm{~L}^{-1}\right.$ sucrose, $0.2 \mathrm{~g} \mathrm{~L}^{-1}$ fructose, and no glucose detected). The FAN concentration was $63 \pm 4 \mu \mathrm{g} \mathrm{L}^{-1}$, which is very low compared to grape must, for example (between 50 and $150 \mathrm{mg} \mathrm{L}^{-1}$ ) [33]. The initial average $\mathrm{pH}$ value was $6.64 \pm 0.47$ units and average total acidity was lower than $1 \mathrm{meq} \mathrm{L}^{-1}$. No organic acids nor ethanol were detected. The chemical composition variation of sugared black tea after the incubation of each culture (day 14) is detailed in Table 1. 
Table 1. Change in the chemical composition of sugared black tea by pure cultures of yeast and bacterial strains isolated from black tea kombucha after 14 days in open and closed conditions of incubation.

\begin{tabular}{|c|c|c|c|c|c|c|c|c|c|c|c|c|}
\hline \multirow{2}{*}{$\begin{array}{c}\text { Microorganism } \\
\text { Incubation Condition }\end{array}$} & \multicolumn{2}{|c|}{ B. bruxellensis } & \multicolumn{2}{|c|}{ H. valbyensis } & \multicolumn{2}{|c|}{ S. cerevisiae } & \multicolumn{2}{|c|}{ A. indonesiensis } & \multicolumn{2}{|c|}{ A. papayae } & \multicolumn{2}{|c|}{ K. saccharivorans } \\
\hline & $\begin{array}{l}\text { Open } \\
\text { Vessel }\end{array}$ & $\begin{array}{l}\text { Closed } \\
\text { Vessel }\end{array}$ & $\begin{array}{l}\text { Open } \\
\text { Vessel }\end{array}$ & $\begin{array}{l}\text { Closed } \\
\text { Vessel }\end{array}$ & $\begin{array}{l}\text { Open } \\
\text { Vessel }\end{array}$ & $\begin{array}{l}\text { Closed } \\
\text { Vessel }\end{array}$ & $\begin{array}{l}\text { Open } \\
\text { Vessel }\end{array}$ & $\begin{array}{c}\text { Closed } \\
\text { Vessel }\end{array}$ & $\begin{array}{l}\text { Open } \\
\text { Vessel }\end{array}$ & $\begin{array}{l}\text { Closed } \\
\text { Vessel }\end{array}$ & $\begin{array}{l}\text { Open } \\
\text { Vessel }\end{array}$ & $\begin{array}{l}\text { Closed } \\
\text { Vessel }\end{array}$ \\
\hline$\Delta$ Total sugars $\left(\mathrm{g} \mathrm{L}^{-1}\right) *$ & $-10.7^{a}$ & $-10.6^{a}$ & $-2.2^{a}$ & $-9.4^{\mathrm{a}}$ & $0.0^{\mathrm{a}}$ & $-7.9^{a}$ & $-3.6^{a}$ & $-0.9^{a}$ & $-0.7^{\mathrm{a}}$ & $0.0^{\mathrm{a}}$ & $-6.2^{a}$ & $-10.0^{a}$ \\
\hline$\Delta$ Glucose $\left(\mathrm{g} \mathrm{L}^{-1}\right)$ & $27.0^{\mathrm{a}}$ & $26.9^{a}$ & $0.0^{\mathrm{d}}$ & $0.9^{\mathrm{d}}$ & $18.9^{b}$ & $28.5^{\mathrm{a}}$ & $2.1^{\mathrm{d}}$ & nd & nd & nd & $4.2^{\mathrm{d}}$ & $9.0^{c}$ \\
\hline$\Delta$ Fructose $\left(\mathrm{g} \mathrm{L}^{-1}\right)$ & $29.8^{a}$ & $30.8^{a}$ & $0.0^{\mathrm{d}}$ & $5.0^{c}$ & $17.2^{b}$ & $31.8^{\mathrm{a}}$ & $1.1^{\mathrm{cd}}$ & nd & $0.2^{\mathrm{d}}$ & $0.4^{\mathrm{d}}$ & $1.9 \mathrm{~cd}$ & $0.6^{\mathrm{d}}$ \\
\hline$\Delta$ Ethanol $\left(\mathrm{g} \mathrm{L}^{-1}\right)$ & $3.2^{\mathrm{a}}$ & $2.5^{b}$ & $0.1^{\mathrm{d}}$ & $1.5^{\mathrm{c}}$ & $0.4^{\mathrm{d}}$ & $2.4^{\mathrm{b}}$ & nd & $<0.1$ & nd & nd & nd & $<0.1$ \\
\hline$\Delta$ Free amino nitrogen $\left(\mu \mathrm{g} \mathrm{L}^{-1}\right)$ & $37^{\mathrm{a}}$ & $52^{\mathrm{a}}$ & $7^{\mathrm{b}}$ & $31^{\mathrm{ab}}$ & $3^{\mathrm{b}}$ & $54^{\mathrm{a}}$ & $3^{b}$ & $30 \mathrm{ab}$ & $8^{\mathrm{b}}$ & $29^{a b}$ & $8^{\mathrm{b}}$ & $28^{\mathrm{ab}}$ \\
\hline$\Delta$ Total acidity $\left(\right.$ meq L L $\left.^{-1}\right)$ & $8.0^{\mathrm{abc}}$ & $6.3^{a b c}$ & $2.0^{\mathrm{c}}$ & $6.7^{\mathrm{abc}}$ & $1.0^{\mathrm{c}}$ & $4.7^{\mathrm{bc}}$ & $11.0^{\mathrm{abc}}$ & $19.3^{\mathrm{a}}$ & $7.0^{a b c}$ & $5.7^{\mathrm{bc}}$ & $19.3^{\mathrm{a}}$ & $16.7^{\mathrm{ab}}$ \\
\hline$\Delta$ Acetic acid $\left(\mathrm{g} \mathrm{L}^{-1}\right)$ & $0.38^{\mathrm{a}}$ & $0.25^{\mathrm{a}}$ & nd & $<0.1$ & $<0.1$ & nd & $0.25^{\mathrm{a}}$ & $0.49^{\mathrm{a}}$ & $0.28^{\mathrm{a}}$ & $0.38^{\mathrm{a}}$ & $0.40^{\mathrm{a}}$ & $0.56^{\mathrm{a}}$ \\
\hline$\Delta$ Gluconic acid $\left(\mathrm{g} \mathrm{L}^{-1}\right)$ & $<0.05$ & $<0.05$ & $<0.05$ & $<0.05$ & $<0.05$ & $<0.05$ & $0.91^{\mathrm{a}}$ & $0.11^{\mathrm{b}}$ & $0.56^{\mathrm{ab}}$ & $0.18^{\mathrm{b}}$ & $1.94^{\mathrm{a}}$ & $0.12^{\mathrm{b}}$ \\
\hline$\Delta$ Lactic acid $\left(\mathrm{g} \mathrm{L}^{-1}\right)$ & nd & nd & $0.46^{\mathrm{a}}$ & $0.20^{\mathrm{abc}}$ & $0.32^{a b}$ & nd & nd & nd & nd & nd & $<0.1$ & nd \\
\hline$\Delta$ Succinic acid $\left(\mathrm{g} \mathrm{L}^{-1}\right)$ & $1.27^{\mathrm{a}}$ & $1.19^{\mathrm{a}}$ & $0.11^{\mathrm{c}}$ & $0.76^{\mathrm{b}}$ & $0.34^{\mathrm{c}}$ & $1.27^{\mathrm{a}}$ & $<0.1$ & $<0.1$ & nd & nd & $0.14^{c}$ & $0.16^{\mathrm{c}}$ \\
\hline$\Delta$ Malic acid $\left(\mathrm{g} \mathrm{L}^{-1}\right)$ & $0.92^{\mathrm{a}}$ & $1.4^{\mathrm{a}}$ & nd & $1.00^{\mathrm{a}}$ & nd & $1.24^{\mathrm{a}}$ & nd & $0.22^{b}$ & $<0.1$ & $0.18^{b}$ & nd & $<0.1$ \\
\hline
\end{tabular}

$*: \Delta$ Concentration $=\Delta$ Endpoint concentration $-\Delta$ Initial concentration $;$ nd $=$ not detected; common letters imply non-significant differences between average values (ANOVA test with $\alpha=0.05$ and $n=3$ ) 
For yeasts, the decrease of total sugars indicated a maximal sugar variation of $-10.7 \mathrm{~g} \mathrm{~L}^{-1}$. No groups could be formed among the different values, despite significant differences $(p<0.05)$. Sucrose underwent variations from null to total disappearance $\left(-68.3 \mathrm{~g} \mathrm{~L}^{-1}\right)$, with significant differences between the values $(p<0.05)$. The monosaccharide content varied significantly from 0.0 to $28.5 \mathrm{~g} \mathrm{~L}^{-1}$ for glucose $(p<0.05)$ and from 0.0 to $31.8 \mathrm{~g} \mathrm{~L}^{-1}$ for fructose $(p<0.05)$. Their production succeeded sucrose hydrolysis. A significant production of ethanol was also observed, with variations between 0.1 and 3.2 from 0.0 to $28.5 \mathrm{~g} \mathrm{~L}^{-1}(p<0.05)$, which is representative of the fermentation activity. The results show very different sugar consumption behaviors across the three yeasts species and highlight the link between invertase activity, respiration, and fermentation. B. bruxellensis is characterized by high invertase activity and fermentative metabolism in both open and closed IC. For this strain, ethanol production was significantly higher in open IC than closed IC $(p<0.05)$. The inhibition of alcoholic fermentation under anaerobic conditions is called the Custer effect and was reported for B. bruxellensis $[34,35]$. H. valbyensis is characterized by poor sucrose hydrolysis and fermentative capacities, particularly in open IC. The very low consumption of sucrose was reported in the context of cider production [36]. The same applied to S. cerevisiae in open IC, but the presence of invertase activity is more evident and points to the induction of SUC genes in the presence of a low glucose concentration $[37,38]$. This mechanism allows S. cerevisiae to progressively hydrolyze sucrose and consume monosaccharides, without inducing catabolic repression by glucose. However, oxygen limitation in closed IC induced fermentation and increased sugar consumption (Pasteur effect), as reported by the data summarized in Marques et al. (2016) [39]. According to this review, the increase in sugar consumption may be a consequence of the lower energetic yield of fermentative metabolism compared to respiration. Then, it can be supposed that the low sucrose consumption observed in S. cerevisiae monoculture in open IC is associated with respiratory metabolism, which could also be the case for $H$. valbyensis. In addition, slightly lower glucose concentrations could be observed for modalities associated with fermentative metabolism. Studies have reported preferential glucose consumption during the alcoholic fermentation of grape must [40,41]. The free amino nitrogen (FAN) concentration increased in all modalities between 3 and $54 \mu \mathrm{g} \mathrm{L}^{-1}$ and it also seems to be enhanced by fermentative metabolism induced by oxygen limitations, although a significant increase between open and closed IC was only observed for S. cerevisiae $(p<0.05)$.

The increase in total acidity (between +1 and +8 meq $\mathrm{L}^{-1}$ ) led to a decrease of the $\mathrm{pH}$ value, ranging from -1.7 to -2.7 units. This increase in total acidity was significantly more intense for $B$. bruxellensis compared to $S$. cerevisiae and the increase for $S$. cerevisiae was also more intense than for $H$. valbyensis in open IC $(p<0.05)$. B. bruxellensis is characterized by the production of acetic acid. Indeed, this species is strongly associated with the production of this organic acid [34]. For the whole set of yeasts, the accumulation of succinic and malic acid and the absence of lactic acid production seem to be linked to fermentative metabolism in these conditions.

Despite the initial absence of monosaccharides added, AAB were able to consume between 0.7 and $10 \mathrm{~g} \mathrm{~L}^{-1}$ total sugars. The presence of monosaccharides after 14 days points to the hydrolysis of sucrose in the external medium. This phenomenon has been reported in several studies $[17,42-44]$. The total acidity increased between +5.7 and +19.3 meq $\mathrm{L}^{-1}$ and induced a drop of $\mathrm{pH}$ between -2.05 and -2.64 units, with significant differences between the values $(p<0.05)$. The production of gluconic acid from the oxidation of released glucose between +0.11 and $+1.94 \mathrm{~g} \mathrm{~L}^{-1}$ was significantly lower with closed IC for all AAB species except $A$. papayae $(p<0.05)$ and could be explained by the limitation of oxygen [7]. The production of acetic acid between +0.25 and $+0.56 \mathrm{~g} \mathrm{~L}^{-1}$ without the initial presence of ethanol can be explained through the glycolysis and pyruvate metabolism of AAB [44-46] and has been reported in the study of Wang et al. (2020) [17]. Succinic acid production occurred between +0.14 and $+0.16 \mathrm{~g} \mathrm{~L}^{-1}$ for $\mathrm{K}$. saccharivorans monocultures and malic acid production only occurred for Acetobacter sp. cultures in closed IC. It is worth noting that no consistent biofilm was produced after 14 days in all conditions; only floating cellulose fragments were visible. Overall, AAB could 
hydrolyze sucrose and consume monosaccharides. Oxygen limitations in closed IC impacted oxidative metabolism converting glucose into gluconic acid, and thus a limited acidification of the medium.

The interpretation of coculture results in comparison with original kombucha fermentation on the basis of monoculture characterization will help clarify the impact of each metabolic profile on the yeast- $\mathrm{AAB}$ interactions.

\subsection{Comparison of Yeast-Acetic Acid Bacteria Cocultures with Original Kombucha Fermentation}

\subsubsection{Microbial Dynamics}

The experimental plan for yeast-AAB cocultures and their abbreviations are presented in Table 2. These pairings can be seen as minimal kombucha consortia that allow the metabolic interplay necessary for the fermentation of kombucha. This process occurred at $26^{\circ} \mathrm{C}$ in two phases: An initial 14-day phase in open IC and a second phase of 10 days in closed IC.

Table 2. "Yeast x Acetic acid bacteria" couples used for cocultures.

\begin{tabular}{cccc}
\hline Cocultures & $\begin{array}{c}\text { Acetobacter } \\
\text { indonesiensis }\end{array}$ & $\begin{array}{c}\text { Acetobacter } \\
\text { papayae }\end{array}$ & $\begin{array}{c}\text { Komagataeibacter } \\
\text { saccharivorans }\end{array}$ \\
\hline Brettanomyces bruxellensis & $\mathrm{BB} \times \mathrm{AI}$ & $\mathrm{BB} \times \mathrm{AP}$ & $\mathrm{BB} \times \mathrm{KS}$ \\
Hanseniaspora valbyensis & $\mathrm{HV} \times \mathrm{AI}$ & $\mathrm{HV} \times \mathrm{AP}$ & $\mathrm{HV} \times \mathrm{KS}$ \\
Saccharomyces cerevisiae & $\mathrm{SC} \times \mathrm{AI}$ & $\mathrm{SC} \times \mathrm{AP}$ & $\mathrm{SC} \times \mathrm{KS}$ \\
\hline
\end{tabular}

All yeast populations in coculture (Figure 2a,c,e) at day 14 remained significantly lower (1 to 0.5 $\log$ ) than those in yeast monocultures at day 14 in open IC (Figure 1). This could mean that the presence of AAB lowered the population of yeasts, regardless of the species. Possible explanations could be nutritional competition [1] or inhibition through the production of acetic acid (see Table 3) $[47,48]$. AAB populations increased significantly above $1.10^{5} \mathrm{CFU} \mathrm{mL} \mathrm{m}^{-1}$ at day 7. Only cocultures $\mathrm{BB} \times \mathrm{AP}$, $\mathrm{BB} \times \mathrm{KS}$, and HV $\times \mathrm{AI}$ (Figure $2 \mathrm{~b}, \mathrm{~d}, \mathrm{f}$ ) reached bacterial populations beyond $1.10^{6} \mathrm{CFU} \mathrm{mL}^{-1}$ on day 7. Between day 14 and day 24 , populations remained stable in the range between $1.10^{5}$ and $1.10^{6}$ $\mathrm{CFU} \mathrm{mL}{ }^{-1}$. The strongest variations could be seen with the modalities SC $x$ AP and SC $x$ KS, with populations below $1.10^{5} \mathrm{CFU} \mathrm{mL} \mathrm{mL}^{-1}$. Populations of Acetobacter sp. in coculture at day 14 were lower than those in monocultures in open IC at day 14 by around $1 \mathrm{log}$. On the contrary, populations of $K$. saccharivorans were higher in cocultures by around $1.5 \mathrm{log}$. 
(a)

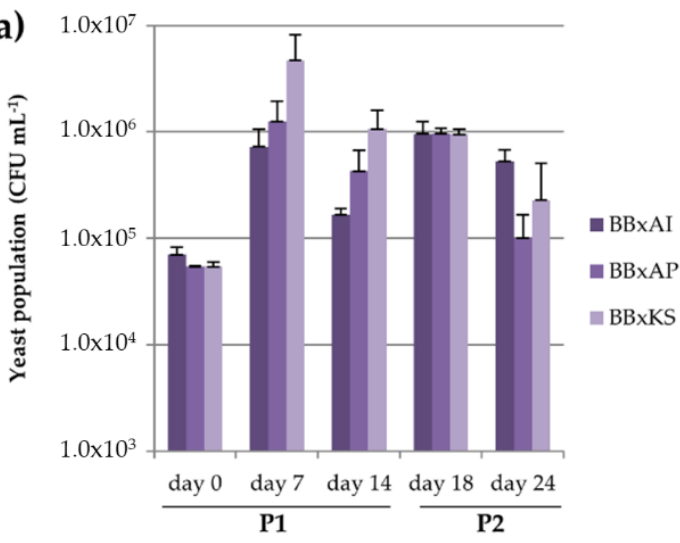

(c)

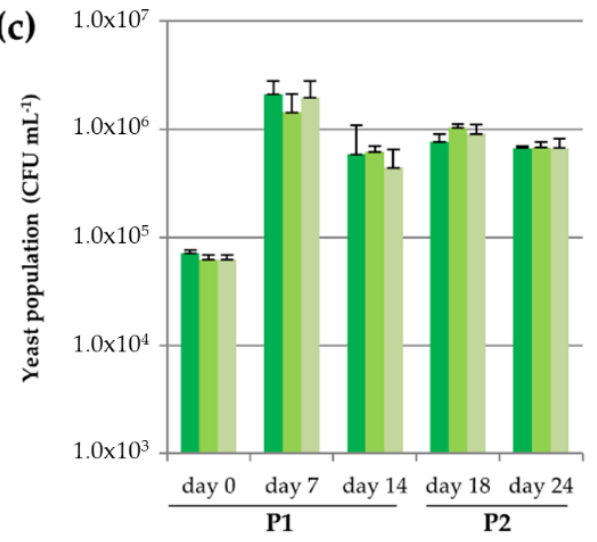

(e)

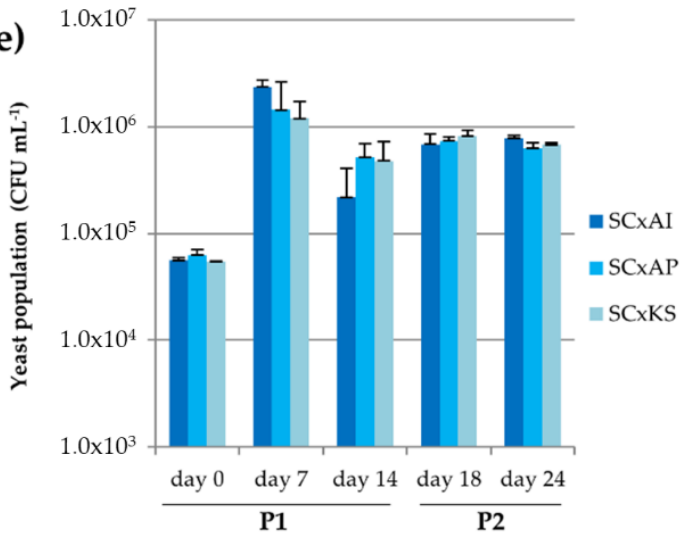

(b)

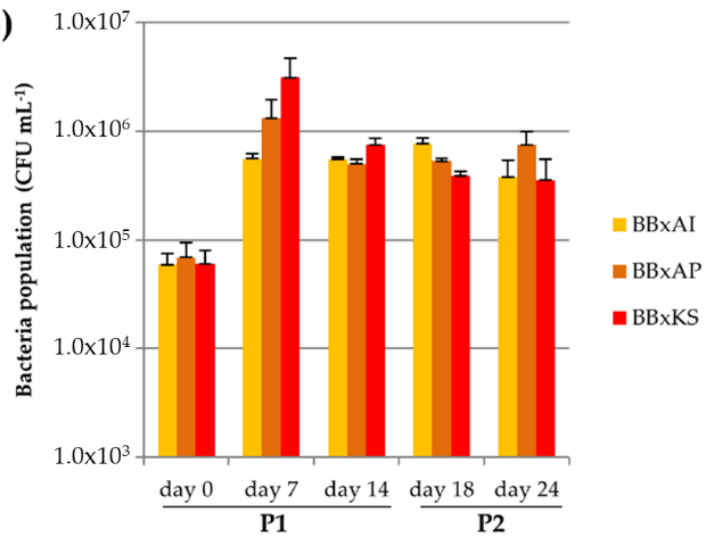

(d)

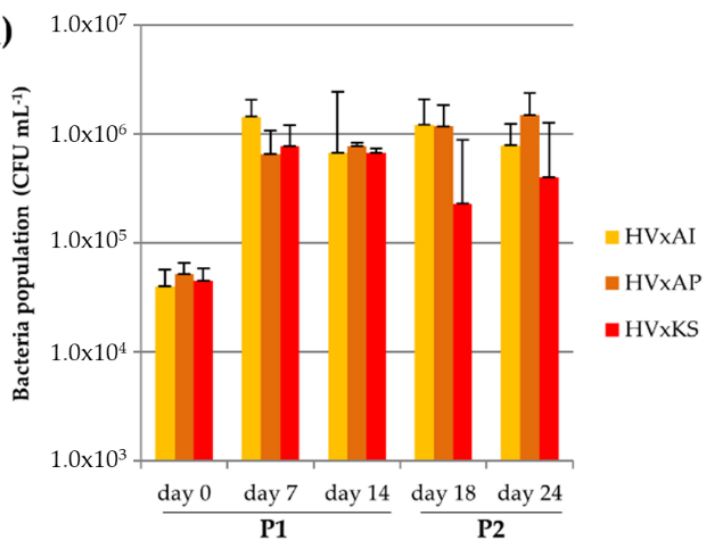

(f)

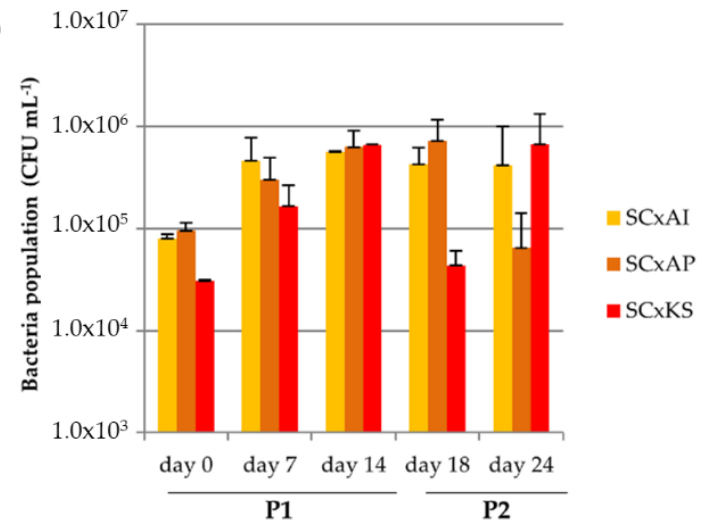

Figure 2. Microbial populations of yeast and bacterial cocultures in sugared black tea determined by plate counting ( $\left.\mathrm{CFU} \mathrm{mL}{ }^{-1}\right)$. Error bars correspond to the confidence interval with $\alpha=0.05(n=3)$. (a) and (b) Yeast and bacterial populations, respectively, in cocultures involving Brettanomyces bruxellensis (BB). (c) and (d) Yeast and bacterial populations, respectively, in cocultures involving Hanseniaspora valbyensis (HV). (e) and (f) Yeast and bacterial populations, respectively, in cocultures involving Saccharomyces cerevisiae $(\mathrm{SC}) . \mathrm{AI}=$ Acetobacter indonesiensis, $\mathrm{AP}=$ Acetobacter papayae, and $\mathrm{KS}=$ Komagataeibacter saccharivorans. 
Table 3. Difference in the organic acid content of samples between day 0 (after inoculation) and the end point (14 days for pure cultures, 14 days in an open vessel for P1, and 10 days in a closed vessel following P1 for P2).

\begin{tabular}{|c|c|c|c|c|c|c|}
\hline $\begin{array}{c}\text { Fermentation } \\
\text { Phase }\end{array}$ & Coculture & $\begin{array}{c}\Delta \text { Acetic } \\
\text { Acid }\left(g^{-1}\right)\end{array}$ & $\begin{array}{c}\Delta \text { Gluconic } \\
\text { Acid }\left(\mathrm{g} \mathrm{L}^{-1}\right)\end{array}$ & $\begin{array}{c}\Delta \text { Lactic } \\
\text { Acid }\left(\mathrm{g} \mathrm{L}^{-1}\right)\end{array}$ & $\begin{array}{c}\Delta \text { Succinic } \\
\text { Acid }\left(g^{-1}\right)\end{array}$ & $\begin{array}{l}\Delta \text { Malic Acid } \\
\quad\left(\mathrm{g} \mathrm{L}^{-1}\right)\end{array}$ \\
\hline \multirow{10}{*}{$\begin{array}{c}\text { P1 } \\
\text { Open vessel } \\
\text { (14 days })\end{array}$} & $\mathrm{BB} \times \mathrm{AI}$ & $0.7^{\mathrm{bcd}}$ & $1.6^{a b c}$ & nd & $0.3^{a b c}$ & nd \\
\hline & $\mathrm{BB} \times \mathrm{AP}$ & $0.6^{b c d}$ & $1.4^{\mathrm{abcd}}$ & nd & $0.3^{a b c}$ & nd \\
\hline & $\mathrm{BB} \times \mathrm{KS}$ & $2.7^{b c}$ & $1.7^{\mathrm{ab}}$ & nd & nd & nd \\
\hline & $\mathrm{HV} \times \mathrm{AI}$ & nd & $0.1^{\text {ef }}$ & $0.3^{\mathrm{a}}$ & $0.2^{b c}$ & nd \\
\hline & $\mathrm{HV} \times \mathrm{AP}$ & $0.2 \mathrm{~cd}$ & $0.1^{\mathrm{f}}$ & $0.4^{\mathrm{a}}$ & $0.2^{a b c}$ & nd \\
\hline & $\mathrm{HV} \times \mathrm{KS}$ & $0.4^{\mathrm{c}}$ & $<0.05$ & $0.2^{b c}$ & $0.2^{a b c}$ & $0.3^{a}$ \\
\hline & $\mathrm{SC} \times \mathrm{AI}$ & $1.0 \mathrm{bcd}$ & 1.2 abcde & nd & $0.3^{a b c}$ & nd \\
\hline & $\mathrm{SC} \times \mathrm{AP}$ & $0.8^{c}$ & $2.2^{a}$ & nd & $0.3^{a b c}$ & nd \\
\hline & $\mathrm{SC} \times \mathrm{KS}$ & $2.7^{b c d}$ & $1.3^{\text {abcde }}$ & nd & $0.4^{a b c}$ & nd \\
\hline & Kombucha & $1.6^{\mathrm{bcd}}$ & $1.7^{\mathrm{ab}}$ & $0.1^{c}$ & $0.2^{a b c}$ & nd \\
\hline \multirow{10}{*}{$\begin{array}{c}\text { P2 } \\
\text { Closed } \\
\text { vessel } \\
\text { (10 days } \\
\text { after P1) }\end{array}$} & $\mathrm{BB} \times \mathrm{AI}$ & $2.0^{\mathrm{bcd}}$ & $1.6^{\mathrm{abc}}$ & nd & $0.6^{a b c}$ & nd \\
\hline & $\mathrm{BB} \times \mathrm{AP}$ & $1.6^{\mathrm{bcd}}$ & $1.2^{\text {abcde }}$ & nd & $0.7^{\mathrm{ab}}$ & nd \\
\hline & $\mathrm{BB} \times \mathrm{KS}$ & $12.7^{a}$ & $2.0^{a}$ & nd & nd & nd \\
\hline & $\mathrm{HV} \times \mathrm{AI}$ & $0.7^{\mathrm{cd}}$ & $0.3^{\text {def }}$ & $0.2^{b c}$ & $0.7^{\mathrm{ab}}$ & $1.0^{\mathrm{a}}$ \\
\hline & $\mathrm{HV} \times \mathrm{AP}$ & $2.4^{b c d}$ & $0.5^{\text {cdef }}$ & $0.1^{\mathrm{cd}}$ & $0.7^{a b}$ & nd \\
\hline & $\mathrm{HV} \times \mathrm{KS}$ & $2.9^{b c d}$ & $0.4^{\text {def }}$ & $0.3^{a b}$ & $0.5^{a b c}$ & $0.2^{a}$ \\
\hline & $\mathrm{SC} \times \mathrm{AI}$ & $2.2^{b c d}$ & $2.3^{a}$ & nd & $0.8^{a}$ & nd \\
\hline & $\mathrm{SC} \times \mathrm{AP}$ & $2.2^{b c d}$ & $2.4^{\mathrm{a}}$ & nd & $0.8^{a}$ & nd \\
\hline & SC $x \mathrm{KS}$ & $11.3^{a}$ & $2.2^{\mathrm{a}}$ & nd & nd & nd \\
\hline & Kombucha & $2.1 \mathrm{bcd}$ & $0.8^{\text {bcdef }}$ & $0.1^{\mathrm{cd}}$ & $0.3^{a b c}$ & nd \\
\hline
\end{tabular}

ANOVA was performed with $\alpha=0.05$ and $n=3$, and common letters imply non-significant differences between means. $\mathrm{BB}=$ Brettanomyces bruxellensis, $\mathrm{HV}=$ Hanseniaspora valbyensis, $\mathrm{HO}=$ Hanseniaspora opuntiae, $\mathrm{SC}=$ Saccharomyces cerevisiae, $\mathrm{AI}=$ Acetobacter indonesiensis, $\mathrm{AP}=$ Acetobacter papayae, $\mathrm{KS}=$ Komagataeibacter saccharivorans, and " $\mathrm{x}$ " = a coculture.

During original kombucha fermentation, total yeasts and total bacterial populations at inoculation

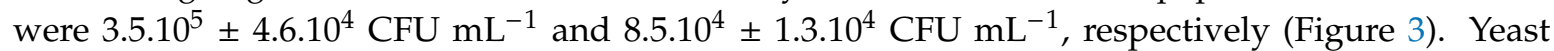
and bacterial populations increased to $3.2 \cdot 10^{6} \pm 1.8 \cdot 10^{6} \mathrm{CFU} \mathrm{mL}^{-1}$ and $1.8 .10^{6} \pm 3.2 .10^{5} \mathrm{CFU} \mathrm{mL}^{-1}$, respectively, and stayed stable until day 24 . The total yeasts population thus remained slightly higher than the total bacteria population throughout the fermentation. This was not observed for cocultures. Both yeast and $\mathrm{AAB}$ populations were lower in cocultures than in original kombucha fermentation (Figure 2). The general higher population in original kombucha could indicate different microbial dynamics of the consortium compared to cocultures. The differences in the yeast/AAB balance could be explained by the absence of consistent pellicle formation in cocultures, with a fragile veil appearing instead. The AAB population present in the biofilm in original kombucha could then be found in the liquid phase of cocultures instead $[49,50]$. The different yeast colony morphotypes allowed a discrimination of populations by species. At the inoculation time, $H$. valbyensis was the major yeast species $\left(6.6 .10^{4} \pm 5.1 .10^{3} \mathrm{CFU} \mathrm{mL} \mathrm{mL}^{-1}\right)$, followed by B. bruxellensis. $\left(2.8 .10^{5} \pm 4.3 .10^{4} \mathrm{CFU}\right.$ $\mathrm{mL}^{-1}$ ). The S. cerevisiae population was clearly lower, with $1.3 \cdot 10^{3} \pm 1.7 .10^{3} \mathrm{CFU} \mathrm{mL}^{-1}$ (Figure 3). After 7 days, all populations increased beyond $5 \log$ and B. bruxellensis became the major species, followed by $H$. valbyensis and then $S$. cerevisiae. The same levels of population were found at day 14 . It is worth noting that these proportions differ in comparison to those of the inoculum (fermentation of 14 days) 
and consequently the sample at day 0 (inoculation). This could be explained by differences in oxygen access due to the greater SIS of the preculture compared to the SIS used during the experiment. Change occurred at day 18 and day 24 after closing the bottle, with a parallel decrease of the $H$. valbyensis population $\left(-2.7 .10^{5} \mathrm{CFU} \mathrm{mL} \mathrm{m}^{-1}\right)$ at day 24 and an increase of $S$. cerevisiae $\left(+1.8 .10^{5} \mathrm{CFU} \mathrm{mL}^{-1}\right)$. The $B$. bruxellensis population remained stable between day 7 and day 24 , which highlights a predominant role during the whole process. The population dynamics induced by vessel closing were not observable in cocultures (Figure 2).

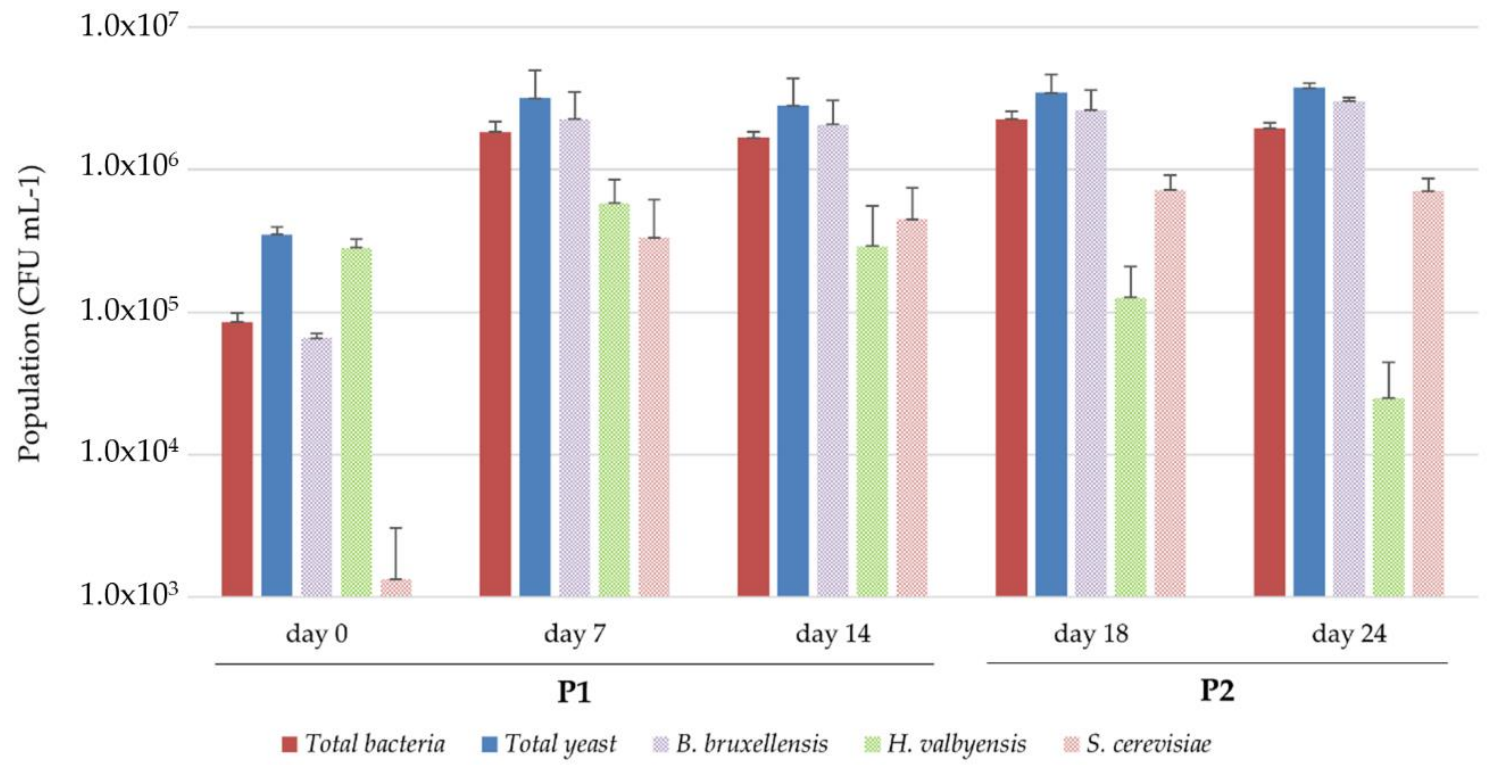

Figure 3. Microbial populations during cultivation in sugared black tea of the black tea kombucha consortium determined by plate counting $\left(\mathrm{CFU} \mathrm{mL}{ }^{-1}\right)$. Error bars correspond to the confidence interval with $\alpha=0.05(n=3)$.

\subsubsection{Utilization of Carbohydrates}

No groups could be determined among the total sugar variation values, ranging between -5 and $-27 \mathrm{~g} \mathrm{~L}^{-1}$, despite the presence of significant differences $(p=0.008)$ (Figure 4a). However, the average values of total sugar variations are all lower between the aerobic acidification phase (14 days after inoculation, P1) and anaerobic acidification phase (10 days in closed IC, P2). This means that most of the sugars were consumed during P1. The sucrose hydrolysis of cocultures, reflected by the disappearance of sucrose, was similar to the capacities observed by the corresponding yeast monoculture, except for S. cerevisiae. This species behaved closer to monocultures in the closed IC, with the complete degradation of sucrose during P1 (Figure 4a and Table 1). All cocultures except those including $H$. valbyensis achieved significantly stronger sucrose hydrolysis at P1 compared to kombucha $(p<$ 0.05), but this gap was filled at P2 (Figure 3a). This highlights a strong impact of yeasts on the release of monosaccharides that are used by AAB. The results displayed in Figure 4-b show a significantly greater release of monosaccharides of B. bruxellensis and $S$. cerevisiae compared to $H$. valbyensis, thus confirming the release of glucose and fructose for cocultures including yeasts with strong known invertase activity ( $p<0.05$ for glucose and $p<0.05$ for fructose). It is noteworthy that in all cases at $\mathrm{P} 1$, the fructose content was higher than glucose at $\mathrm{P} 1$ and $\mathrm{P} 2$, which was characteristic of yeast metabolism in monocultures (Table 1), but preference for glucose could also occur for AAB. 
(a) - Total sugars Sucrose
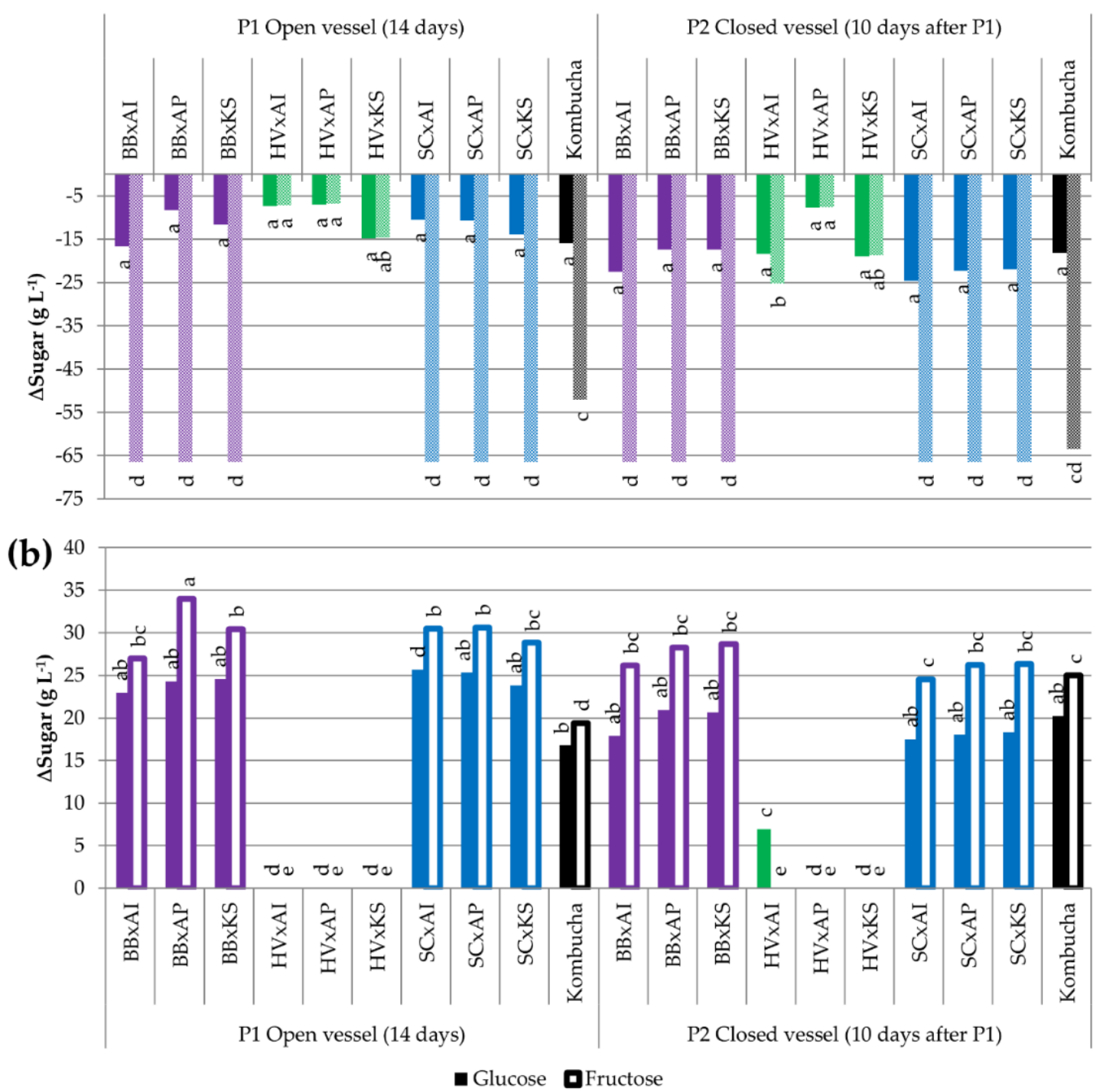

Figure 4. Difference in total sugars and sucrose (a) and in glucose and fructose (b) $\left(\mathrm{g} \mathrm{L}^{-1}\right)$ of samples between day 0 (after inoculation) and the end point (14 days for pure cultures, 14 days in an open vessel for P1, and 10 days in a closed vessel following P1 for P2). ANOVA was performed with $\alpha=0.05$ and $n=3$. Common letters imply non-significant differences between means. Colors reflect the yeast species in the coculture. $\mathrm{BB}=$ Brettanomyces bruxellensis (purple), $\mathrm{HV}=$ Hanseniaspora valbyensis (green), $\mathrm{SC}=$ Saccharomyces cerevisiae (blue), $\mathrm{AI}=$ Acetobacter indonesiensis, $\mathrm{AP}=$ Acetobacter papayae, $\mathrm{KS}=$ Komagataeibacter saccharivorans, and " $\mathrm{x}$ " = a coculture.

Original kombucha underwent an incomplete hydrolysis of sucrose at P1 (-52.0 $\mathrm{g} \mathrm{L}^{-1}$ sucrose), but the process was completed at P2 $\left(-63.4 \mathrm{~g} \mathrm{~L}^{-1}\right.$ sucrose), although the total sugar consumption did not evolve significantly ( -15.9 and $-18.2 \mathrm{~g} \mathrm{~L}^{-1}$ total sugars at $\mathrm{P} 1$ and $\mathrm{P} 2$, respectively; the initial amount of total sugar was $72.5 \mathrm{~g} \mathrm{~L}^{-1}$ with $71 \mathrm{~g} \mathrm{~L}^{-1}$ sucrose and $1.5 \mathrm{~g} \mathrm{~L}^{-1}$ fructose, and glucose was not detected). It can be supposed that the conditions in original kombucha led to a different rate of substrate consumption.

\subsubsection{Variations in Ethanol Content}

The ethanol increase was lower at P1 (from +0.3 to $+1.2 \mathrm{~g} \mathrm{~L}^{-1}$ ) than P2 because of the inhibition of oxidative metabolism with oxygen deprivation (from +0.5 to $+4.3 \mathrm{~g} \mathrm{~L}^{-1}$ ) (Figure 5). The production of 
ethanol by cocultures involving S. cerevisiae at P1 was higher than those occurring in monocultures in open IC $\left(+0.1 \mathrm{~g} \mathrm{~L}^{-1}\right)$ (Table 3$)$. This shows that this species in cocultures switched to fermentative metabolism, even in open IC. This switch also involved an increase in invertase activity due to the lower energetic yield of glucose consumed through fermentation compared to respiration (Figure 3). Between $\mathrm{P} 1$ and $\mathrm{P} 2$, the ethanol content increased significantly for $\mathrm{BB} \times \mathrm{AI}, \mathrm{BB} \times \mathrm{AP}, \mathrm{HV} \times \mathrm{AP}$, and all cocultures involving S. cerevisiae $(p<0.05)$. The ethanol production of original kombucha was $+1.0 \mathrm{~g} \mathrm{~L}^{-1}$ at $\mathrm{P} 1$, with no significant variation at P2. Most ethanol production was significantly higher in cocultures, except $\mathrm{BB} \times \mathrm{KS}, \mathrm{HV} \times \mathrm{AI}$, and $\mathrm{HV} \times \mathrm{KS}$. This could suggest that biological ethanol oxidation is influenced by microbial dynamics. The presence of the pellicle in original kombucha could play a specific role in the enhancement of ethanol oxidation in particular.

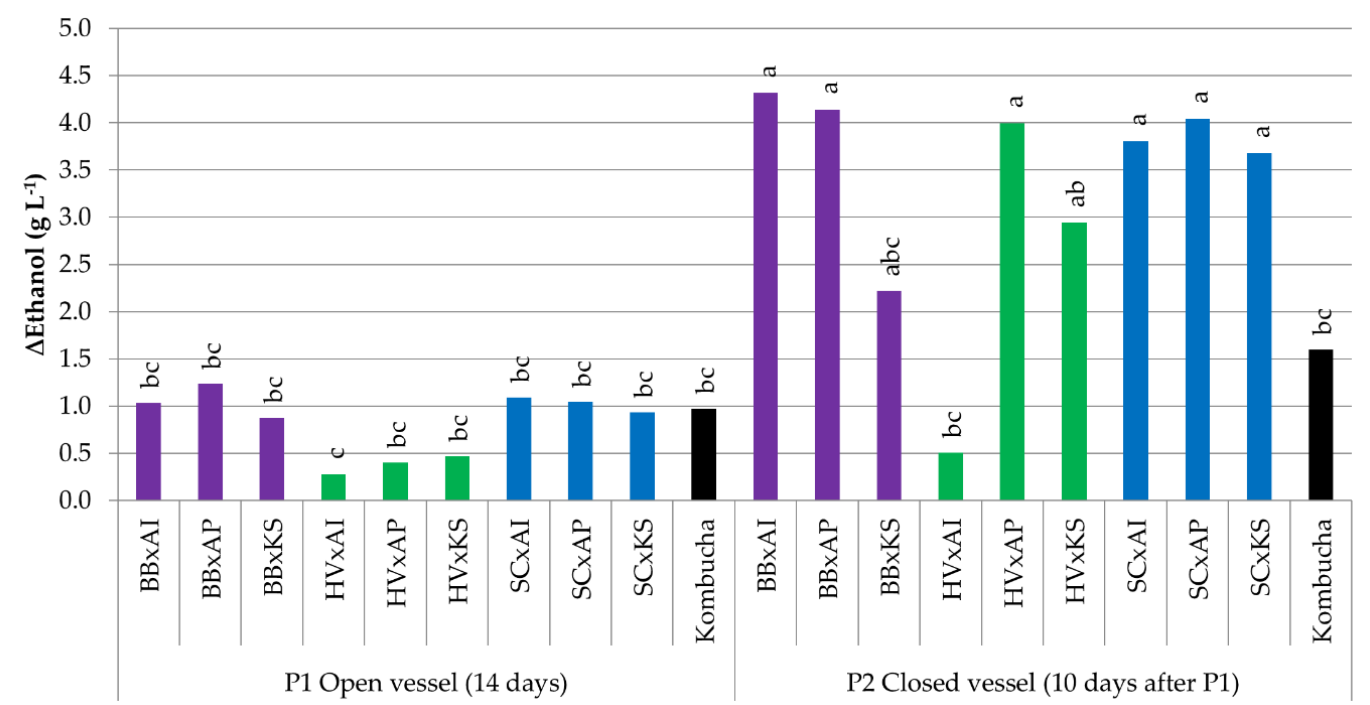

Figure 5. Difference in ethanol ( $\mathrm{g} \mathrm{L}^{-1}$ ) of samples between day 0 (after inoculation) and the end point (14 days for pure cultures, 14 days in an open vessel for P1, and 10 days in a closed vessel for P2 following P1). ANOVA was performed with $\alpha=0.05$ and $n=3$. Common letters imply non-significant differences between means. Colors reflect the yeast species in the coculture. $\mathrm{BB}=$ Brettanomyces bruxellensis (purple), $\mathrm{HV}=$ Hanseniaspora valbyensis (green), SC = Saccharomyces cerevisiae (blue), $\mathrm{AI}=$ Acetobacter indonesiensis, $\mathrm{AP}=$ Acetobacter papayae, $\mathrm{KS}=$ Komagataeibacter saccharivorans, and " $\mathrm{x}$ " = a coculture.

\subsubsection{Variations in the Free Amino Nitrogen Content}

An increase of the FAN concentration between +19 and $+80 \mu \mathrm{g} \mathrm{L}-1$ was also observed in cocultures compared to sugared tea (initial average concentration of $63 \mu \mathrm{g} \mathrm{L}^{-1}$ ) (Figure 6). The FAN increase was significantly lower for HV $\times$ KS compared to BB $\times$ KS and SC $\times$ KS at P1 $(p<0.05)$. The FAN increase in original kombucha was $12 \mu \mathrm{g} \mathrm{L}{ }^{-1}$ at $\mathrm{P} 1$ and was not significantly different compared to P2. The fact that FAN increases were similar between P1 and P2 suggests that oxygen deprivation could occur at P1 in cocultures because of the oxidative metabolism of $\mathrm{AAB}$, as this behavior contrasts with that of yeast monocultures (Table 1). 


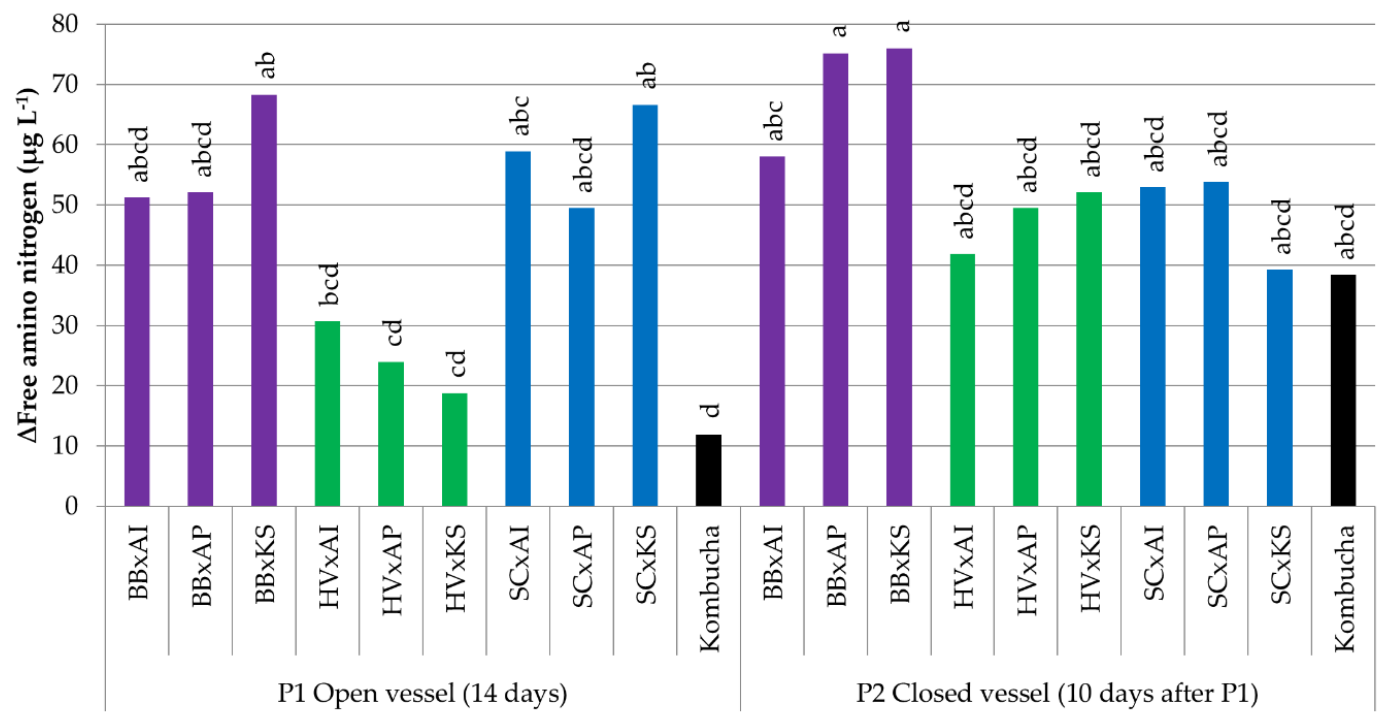

Figure 6. Difference in free amino nitrogen $\left(\mu \mathrm{g} \mathrm{L}^{-1}\right)$ of samples between day 0 (after inoculation) and the end point (14 days for pure cultures, 14 days in an open vessel for P1, and 10 days in a closed vessel for P2 following P1). ANOVA was performed with $\alpha=0.05$ and $n=3$. Common letters imply non-significant differences between means. Colors reflect the yeast species in the coculture. $\mathrm{BB}=$ Brettanomyces bruxellensis (purple), $\mathrm{HV}=$ Hanseniaspora valbyensis (green), $\mathrm{SC}=$ Saccharomyces cerevisiae (blue), $\mathrm{AI}=$ Acetobacter indonesiensis, $\mathrm{AP}=$ Acetobacter papayae, $\mathrm{KS}=$ Komagataeibacter saccharivorans, and " $\mathrm{x}$ " $=$ a coculture.

\subsubsection{Acidification by the Production of Organic Acids}

The $\mathrm{pH}$ of all cocultures dropped between -2 and -4 units (initial average of 6.64) and the total acidity increased from +4 to +70 meq $\mathrm{L}^{-1}$ (initial value $<1$ meq $\mathrm{L}^{-1}$ ) (Figure 7 ). After 14 days, cocultures involving $H$. valbyensis displayed a drop of $\mathrm{pH}$ that was significantly weaker than the others $(p<0.05)$ and their average total acidity values were the lowest $(p<0.05)$. Between P1 and P2, a significative drop of $\mathrm{pH}$ could be observed for HV $\times$ AP and HV $\times$ KS only $(p<0.05)$. Moreover, the total acidity increased significantly for $\mathrm{BB} \times \mathrm{KS}, \mathrm{HV} \times \mathrm{AP}, \mathrm{HV} \times \mathrm{KS}$, and all cocultures involving S. cerevisiae, which suggests that the oxidative metabolism of $\mathrm{AAB}$ was maintained after the closing of the vessel. This could have been allowed by the presence of residual oxygen after the closing of bottles.

The drop of $\mathrm{pH}$ of original kombucha remained the same at $\mathrm{P} 1$ and $\mathrm{P} 2$, with -1.7 units (average initial $\mathrm{pH}$ of 6.04). The increase of total acidity was $+47 \mathrm{meq} \mathrm{L}^{-1}$ at $\mathrm{P} 1$ and +63.7 meq $\mathrm{L}^{-1}$ at $\mathrm{P} 2$, but these average values were not significantly different (average initial total acidity of $3 \pm 1 \mathrm{meq} \mathrm{L}^{-1}$ ). It is noticeable that despite having one of the highest values for the total acidity, the $\mathrm{pH}$ decrease of original kombucha was less intense than all cocultures and supposes a stronger buffering capacity. While a consistent cellulosic biofilm was present in original kombucha, no consistent pellicle was visible for cocultures. Instead, cellulosic fragments were floating at the surface. Therefore, in the absence of a consistent pellicle, cocultures were able to produce organic acids in similar quantities to original kombucha, which implies that the biofilm is not necessary to complete the P1 phase. 

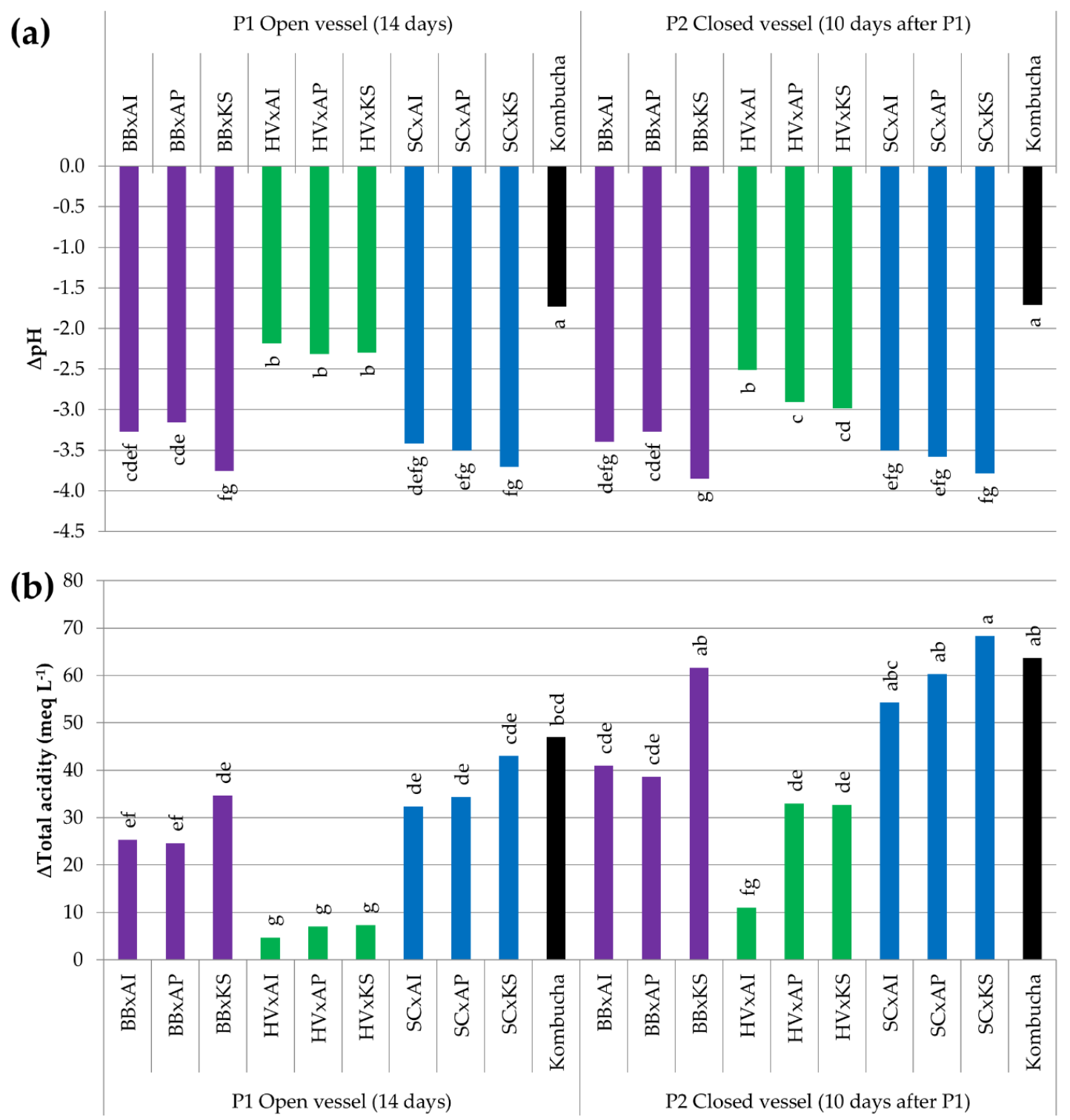

Figure 7. Difference in the (a) $\mathrm{pH}$ value (arbitrary unit) and (b) total acidity (meq L ${ }^{-1}$ ) of samples between day 0 (after inoculation) and the end point (14 days for pure cultures, 14 days in an open vessel for P1, and 10 days in a closed vessel following P1 for P2). ANOVA was performed with $\alpha=0.05$ and $n=3$. Common letters imply non-significant differences between means. Colors reflect the yeast species in the coculture. $\mathrm{BB}=$ Brettanomyces bruxellensis (purple), $\mathrm{HV}=$ Hanseniaspora valbyensis (green), $\mathrm{SC}=$ Saccharomyces cerevisiae (blue), $\mathrm{AI}=$ Acetobacter indonesiensis, $\mathrm{AP}=$ Acetobacter papayae, $\mathrm{KS}=$ Komagataeibacter saccharivorans, and " $\mathrm{x}$ " = a coculture.

The production of organic acids in cocultures and original kombucha is detailed in Table 3. No target organic acid could be detected in sugared black tea and among them, no citric acid was detected in any sample.

The main organic acids produced during P1 were acetic and gluconic acids, with the concentration increase ranging below $+2.7 \mathrm{~g} \mathrm{~L}^{-1}$ and below $+2.2 \mathrm{~g} \mathrm{~L}^{-1}$, respectively. The lowest increases were associated with cocultures involving $H$. valbyensis. These organic acids are mainly produced by AAB as a result of oxidative metabolism from ethanol and glucose. At $\mathrm{P} 1$, the gluconic acid concentrations of cocultures involving $H$. valbyensis were significantly lower than those of cocultures involving B. bruxellensis $(p<0.05)$. The results suggest that the production of organic acids reflects the capacity of the paired yeast to make these substrates available, as it has been established that $H$. valbyensis 
possesses poor fermentative and invertase activities. Between P1 and P2, no significant change in the concentration of acetic and gluconic acids occurred for most cocultures, except BB $x$ KS and SC $x$ $\mathrm{KS}$, whose acetic acid concentrations increased from +7.3 to $+12.7 \mathrm{~g} \mathrm{~L}^{-1}(p<0.05)$. This indicates a capacity of $K$. saccharivorans to maintain the production of acetic acid in conditions of oxygen limitations compared to Acetobacter sp., possibly through a pathway other than oxidative metabolism [44,45]. Other organic acids, such as succinic acid, were detected in all cocultures except for BB x KS at P1 and BB $x$ KS and SC $\times$ KS at P2, which suggests a link with the presence of $K$. saccharivorans, especially in oxygen limitation conditions. Malic acid was only detected in HV x KS at P1 and HV x AI and HV $\mathrm{x}$ KS at P2. Lactic acid was only detected in all cocultures involving $H$. valbyensis, which seems to characterize this species (Table 1). The links established between the production of malic, succinic, and lactic acids and the type of metabolism do not appear clearly for cocultures, probably due to the complexification of metabolic pathways in cocultures.

In original kombucha, an increase of acetic acid and gluconic acid production of +1.6 and $+1.7 \mathrm{~g} \mathrm{~L}^{-1}$, respectively (initial average concentrations of acetic acid of $0.4 \mathrm{~g} \mathrm{~L}^{-1}$ and gluconic acid of $0.3 \mathrm{~g} \mathrm{~L}^{-1}$ ) and low production of lactic and succinic acids inferior to $+0.2 \mathrm{~g} \mathrm{~L}^{-1}$ at P1 (lactic and succinic acids not detected at day 0) (Table 3) were observed. Qualitatively, the organic acid composition of kombucha gathers all organic acids detected in cocultures, with the exception of malic acid. On the contrary, lactic acid was detected and was characteristic of cocultures with $H$. valbyensis. Quantitatively, the original kombucha composition in acetic and gluconic matched those of all cocultures involving fermentative yeasts (excluding H. valbyensis) at P1, but at P2, this only applied to cocultures involving Acetobacter sp., since the presence of $K$. saccharivorans induced an intense production of acetic acid that was probably due to the intensification of ethanol through alcoholic fermentation induced by oxygen deprivation. Indeed, this phenomenon did not occur in cocultures including $H$. valbyensis.

The coculture results underline the impact of yeasts and AAB metabolism on the matrix and variation occurring between yeast and $A A B$ species. The use of statistical treatment can help in visualizing the phenomenon occurring in such complex systems and determine the similarities with original kombucha.

\subsubsection{Principle Component Analysis as a Visual Tool for Understanding Complex} Microbial Interactions

Principle Component Analysis (PCA) was performed on cocultures and original kombucha for P1 and P2 separately, in order to characterize the two different phases in terms of the impact on the chemical composition of the sugared tea matrix (microbial population data were excluded). Both PCA possessed a satisfactory sum of proper values with Dim 1 and Dim 2 axes (77.40\% for P1 and $67.91 \%$ for P2).

The parameter plot of P1 (Figure 8a) was primarily structured by the Dim1 axis positively characterized by the glucose, fructose, acetic acid, gluconic acid, ethanol, FAN concentrations, and total acidity $\left(\cos ^{2} \geq 0.7\right)$, and negatively by the $\mathrm{pH}$, and sucrose and lactic acid concentrations $\left(\cos ^{2} \leq-0.7\right)$. Dim1 translated the biological acidification process targeted during P1 in an open vessel. This acidification (increase of total acidity and decrease of $\mathrm{pH}$ ) was mainly caused by the production of acetic and gluconic acids by AAB. Their production was dependent on the release of monosaccharides (glucose and fructose) from sucrose that can efficiently be hydrolyzed by yeast invertase activity. Lactic acid production was associated with low invertase and fermentative activities, as observed in $H$. valbyensis or S. cerevisiae monocultures in open IC and in cocultures with $H$. valbyensis (Tables 1 and 3 ). Dim 2 was positively characterized by total sugars concentrations and negatively characterized by malic acid, and translated differences in the profiles of organic acids from yeasts and the sugar consumption of cocultures. As a result, the sample plot (Figure 8b) coupled with hierarchical clustering discriminated cocultures with different levels. The predominant difference separated cocultures including $H$. valbyensis from other yeasts. This was caused by the low sucrose hydrolysis and fermentative capacity of $H$. valbyensis that prevented the access of $\mathrm{AAB}$ to monosaccharides and ethanol and thus efficient acidification of the medium. Secondarily, the clustering discriminated the cocultures, including 
K. saccharivorans and Acetobacter sp., for all coupled yeasts except S. cerevisiae. Original kombucha belonged to the cluster including $\mathrm{BB} \times \mathrm{KS}$, highlighting the closeness in chemical compositions.

(a)

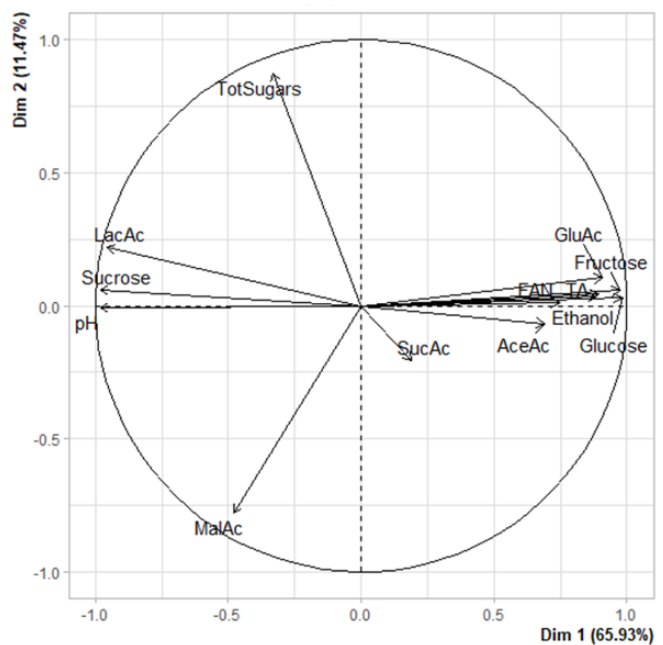

(c)

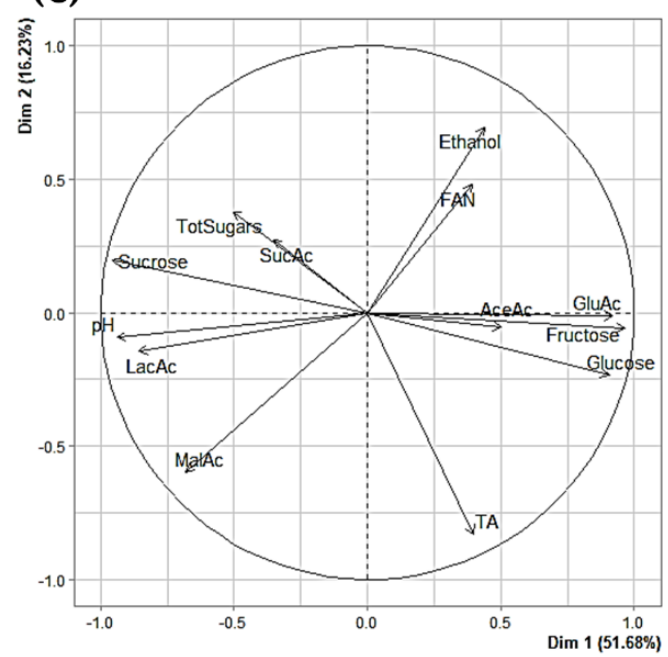

(b)

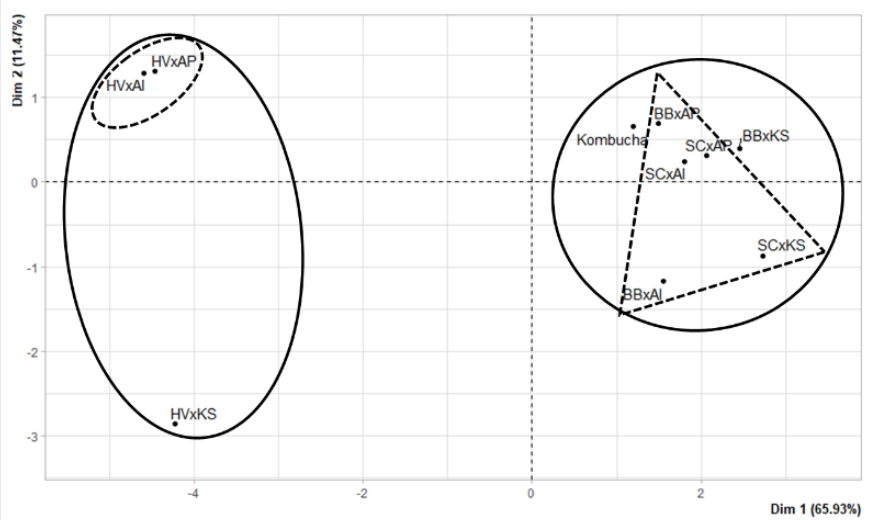

(d)

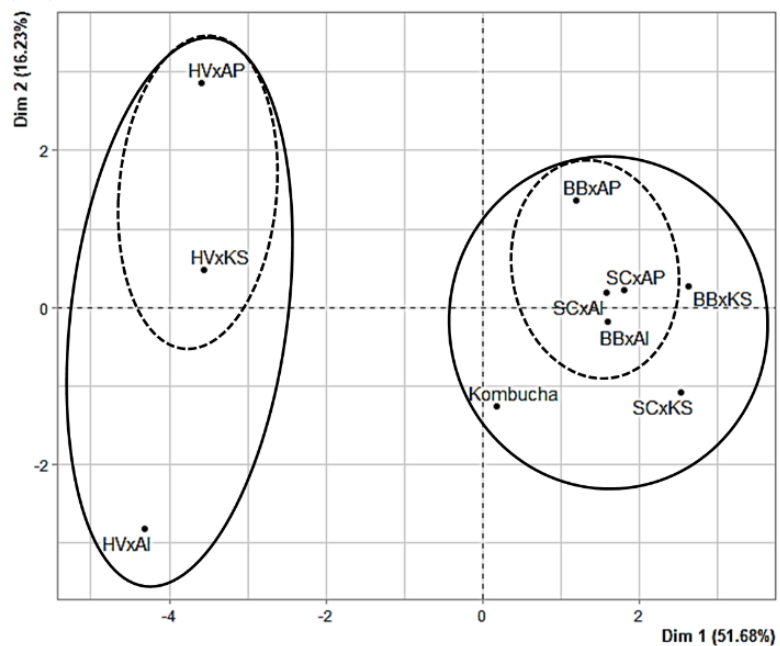

Figure 8. Principle Component Analysis of coculture and original kombucha samples using parameters of the chemical composition. (a) Parameter or vector plot for P1, (b) sample plot for P1, (c) parameter or vector plot for $\mathrm{P} 2$, and (d) sample plot for $\mathrm{P} 2$. Continuous circles gather samples of the same primary clusters and dashed line circles gather samples of the same sub-clusters according to hierarchical ascendant clustering analysis.

The parameter plot of P2 (Figure 8c) was mainly structured by Dim1, which was positively characterized by glucose, fructose, and gluconic acid concentrations $\left(\cos ^{2} \geq 0.7\right)$, and negatively characterized by the $\mathrm{pH}$, and lactic acid and sucrose concentrations. Dim2 was positively characterized by the ethanol concentration and negatively characterized by the total acidity $\left(\cos ^{2} \leq-0.7\right)$. Specifically, Dim 1 could be representative of the invertase activity and Dim2 of AAB activity (oxidation of ethanol and increase of the total acidity). It can be noticed that total sugar and ethanol are not anticorrelated, since, during P1 and even P2, the balance between total sugars and ethanol is biased by its conversion in acetic acid by AAB. The clustering (Figure 8d) again discriminated cocultures including H. valbyensis from the others and cocultures including K. saccharivorans from those with Acetobacter sp. (except for cocultures including $H$. valbyensis). Moreover, original kombucha again belonged to the cluster including BB $\times$ KS and SC $\times$ KS. 
The comparison of parameter plots of P1 and P2 reflects the shift from the combined yeasts and $\mathrm{AAB}$ metabolisms, with a positive correlation of invertase activity, fermentation, and acidification during the acidification phase (all strongly contributing to Dim1) (Figure 8a), towards the prevalence of yeast metabolism (strong contribution to Dim1), with a lower correlation with AAB oxidative metabolism during the carbonation phase (ethanol and total acidity strongly contributing to Dim 2) (Figure 8c).

These results show that yeast metabolism was key throughout the process of fermentation: P1 required yeasts to hydrolyze sucrose and produce ethanol for their conversion into acetic and gluconic acids by $\mathrm{AAB}$ and $\mathrm{P} 2$ relied on fermentation to complete natural carbonation. Nevertheless, K. saccharivorans still strongly impacted the chemical composition during P2 because of its ability to maintain oxidative metabolism, especially when ethanol production is abundant, which was not as visible for Acetobacter sp. More generally, yeast metabolism is the main factor influencing the kombucha composition and the influence of $\mathrm{AAB}$ is secondary and mostly impacts the organic acid profile.

\subsection{Sucrose Utilization Strategies as a Basis of Microbial Interactions in Kombucha}

The experimental results obtained in this study confirm the metabolic interplay between yeasts and acetic acid bacteria that has been theorized for kombucha made from sugared black tea $[17,49,51,52]$. They highlight, for the first time, the key role of yeasts and their metabolisms in terms of invertase activity and the fermentation capacity, which can differ, depending on yeast strains (Table 1). Bibliographic resources and the NCBI database have reported the existence of genes encoding invertase in S. cerevisiae (internal and extracellular enzyme) [53-56] and B. bruxellensis (internal and extracellular enzyme) [5760], but few data is available for $H$. valbyensis. However, genomic studies on the Hanseniaspora genus reported the loss of the SUC gene of the branch to which $H$. valbyensis belongs, thus supporting the low sucrose hydrolysis observed (Table 1) [61]. On top of glucose, fructose, and ethanol, yeasts may also release nitrogenous substrates through the conversion of bound amino-acids, such as proteins and peptides, into free amino acids, since the results suggest a correlation between FAN and fermentation (Figure 8a). Yeast can release free amino acid through extracellular proteolytic activity and/or autolysis [62-65], which could benefit AAB as well [66]. As a result, the metabolism of yeasts directly impacts the flux of available substrates for AAB. Nevertheless, AAB studied in this work were able to grow in sugared black tea without the presence of yeasts to hydrolyze sucrose, similar to the AAB strains used in Wang et al. (2020) [17]. From the perspective of the present results and the experimental conditions of the work cited before, the hypothesis of a snowball effect is supported: Initial spontaneous hydrolysis of sucrose in acidic conditions would be amplified by a pH drop resulting from organic acid production by AAB (Figure S3) [67]. It could even be hypothesized that such a phenomenon also applied for cultures involving H. valbyensis (Table 1, Figures 4 and 7). However, the existence of enzymatic invertase activity in AAB is not to be excluded and more research needs to be carried out in terms of the metabolic pathways of AAB [68]. However, Balasubramaniam and Kannangara (1982) reported low invertase activity of K. xylinus and determined that sucrose consumption was achieved through the activity of sucrose phosphorylase [69]. In all cases, sucrose hydrolysis performed by yeasts except $H$. valbyensis was more efficient than that induced by AAB alone (Table 1). It should be underlined that besides oxidative metabolism, AAB can use monosaccharides through glycolysis, tricarboxylic acids (TCA), and pentose phosphate pathways [46]. The presence of acetic, succinic, and malic acids in $\mathrm{AAB}$ monocultures are markers of these metabolisms (Table 1), in agreement with coculture results. However, the metabolic activity of AAB mostly depends on the substrates released by yeast and the composition in $\mathrm{AAB}$ can impact the profile of produced organic acids (Table 3 and Figure 8).

The microbial dynamics of original kombucha after bottling (P2) were investigated for the first time and highlighted the microbial interaction resulting in the decrease in the population of $H$. valbyensis triggered by oxygen limitations (Figure 3). As S. cerevisiae exhibited more metabolic activity in monocultures and cocultures in oxygen-limited conditions, it can be hypothesized that a negative 
interaction with H. valbyensis could occur in original kombucha. Saccharomyces-non-Saccharomyces interactions have been studied and are not fully understood, but possible mechanisms include the production of toxic compounds [70-73], competition with other nutrients such as sugars or amino acids [74], cell-cell contact mechanisms [75], and flocculation [76]. It was observed that S. cerevisiae's metabolism in cocultures switched to high invertase activity and fermentation during P1 (Figures 4 and 5). This difference of behavior with the monocultures (Table 1) could be explained by an evolutionary mechanism in S. cerevisiae, often compared to "The Prisoner's Dilemma", which modulates its invertase activity according to the presence of "cheaters" without such enzymatic activity $[13,77,78]$. Therefore, the SUC gene coding for the invertase is kept at a minimum expression in monocultures, so that S. cerevisiae can hydrolyze sucrose progressively. A shift to a higher expression level can occur in the presence of other "cheater" species, leading S. cerevisiae to rapidly consume sugars to outgrow other populations and inhibit them through the release of toxic metabolites, such as ethanol [39]. However, in the case of kombucha, this benefits AAB because of the increase of oxidizable substrates and possibly through the increased availability of amino acids. Analytical data regarding oxygen consumption during kombucha fermentation is needed to assess its role in microbial interactions, namely taking into account the presence of the pellicle, which is thought to reduce the access to oxygen in the liquid phase $[50,79]$. It is worth noting that the pellicle was not necessary for AAB in cocultures to perform efficient organic acid production, thus raising questions about additional functions other than facilitating oxygen access to AAB during kombucha fermentation [50].

Differences between cocultures and kombucha also appeared in the chemical composition of the liquid phase. Some kinetics in original kombucha seemed to be intermediate compared to cocultures, especially with sucrose hydrolysis at P1 (Figure 3), the ethanol concentration at P2 (Figure 5), and the FAN concentration (Figure 6). This could be explained by the balance in the yeast population, namely between B. bruxellensis and $H$. valbyensis, which could lead to a leveling of global yeast metabolism during original kombucha fermentation (Figure 3). The role of $H$. valbyensis remains enigmatic regarding the technological aspect of kombucha fermentation. As the present study did not explore volatile compounds, it cannot be excluded that this yeast strain could contribute to the olfactive profile of kombucha beverages. More subtle microbial interactions could also take place in terms of amino acid consumption or chemical signaling between $H$. valbyensis and other yeasts and bacteria [74]. Overall, the results point to an eco-evolution in kombucha between species that possess and do not possess SUC genes necessary for the use of sucrose as a substrate. H. valbyensis and AAB would then be labeled as "cheaters" by taking benefits from the invertase activity of other yeasts, such as $B$. bruxellensis and S. cerevisiae, without contributing themselves to the production of public goods (here, monosaccharides) [80,81]. However, it has been reported in S. cerevisiae x Escherichia coli cocultures that, by lowering the population of public good producers (S. cerevisiae) at high population levels, cheaters (E. coli) could consequently stabilize the sucrose hydrolysis rate, thus maintaining both population levels [78]. A similar phenomenon could also have taken place in the present study, since lower yeast populations in cocultures with $\mathrm{AAB}$ compared to monocultures were also observed (Figures 1 and 2). H. valbyensis and $\mathrm{AAB}$ could therefore contribute to the stability of the community, as it was reported that Hanseniaspora sp. could achieve fast growth due to the evolutionary loss of cell-cycle components, thus limiting nutrient access [82], and acidification of the medium by AAB induced the selection of acidophilic species [83].

\section{Conclusions}

Microbial interactions occurring in kombucha have often been described as "symbiotic", which does not imply mutual benefits, as described by the word "mutualistic", but rather that all species manage a stable coexistence, possibly through interactions that are yet to be defined $[1,13]$. Although the present study lacks an exhaustive insight into the volatile and non-volatile metabolites, it was possible to characterize nutritional interactions. As $\mathrm{AAB}$ are not dependent on yeasts to access substrates, it appears that yeast- $\mathrm{AAB}$ interactions display a non-strict parasitism relationship (as 
sucrose hydrolysis occurred in $\mathrm{AAB}$ monocultures and was sufficient to increase their population at the same level as in original kombucha). No evidence of a beneficial nutritional interaction for yeast could be determined. There is also evidence that $\mathrm{AAB}$ induce the production of substrates by $\mathrm{S}$. cerevisiae by indirectly rerouting its metabolism, thus enhancing the benefits of this parasitic relationship. Moreover, sucrose appears to play a central role in kombucha symbiosis not only in yeast-bacteria interactions, but also potentially between yeast species. While the $\mathrm{AAB}$ composition secondarily impacts the profile in organic acids, the yeast composition in kombucha consortia is crucial for the global microbial dynamics, the chemical composition of the beverage, and the sensory characteristics of the product [9].

This study only includes one kombucha consortium, but many different microbial compositions exist. Nevertheless, many research works have focused on the identification of yeast and bacteria genera and it could be interesting to determine if the yeast profiles include genera or species with variable invertase activities and fermentative capacities. In silico studies relying on genome and protein databases combined with the results of past identification works of kombucha consortia could highlight the existence of patterns in yeast compositions in terms of links between species and activities. Yeast-yeast interactions in the context of kombucha fermentation should also be addressed in future research works, now that the importance of their role has been uncovered.

Supplementary Materials: The following are available online at http://www.mdpi.com/2304-8158/9/7/963/s1, Figure S1: Sum-up diagram of the experiment, Table S2: Description of research samples with abbreviations, Figure S3: Hypothetical "snowball effect" explaining sucrose hydrolysis by acetic acid bacteria.

Author Contributions: Conceptualization, validation, methodology, and visualization, T.T., C.G., and R.T.-M.; resources, F.V., A.M., and H.A.; formal analysis, investigation, data curation, and writing-original draft, T.T.; writing-review and editing, all authors; supervision, C.G., F.V., and R.T.-M.; project administration, A.M. and R.T.-M.; funding acquisition, T.T., C.G., F.V., A.M., and R.T.-M. All authors have read and agreed to the published version of the manuscript.

Funding: This work was supported by the Regional Council of Bourgogne-Franche Comté, the "Fond Européen de DEveloppement Régional (FEDER) and funded by Biomère (Paris, France).

Acknowledgments: The authors thank Laurence Noret for her help with handling and maintaining the HPLC system and Peio Elichiry-Ortiz for setting up and sharing the HPLC method for sugar analysis.

Conflicts of Interest: The authors declare no conflicts of interest.

\section{References}

1. Ivey, M.; Massel, M.; Phister, T.G. Microbial Interactions in Food Fermentations. Annu. Rev. Food Sci. Technol. 2013, 4, 141-162. [CrossRef] [PubMed]

2. Sieuwerts, S.; de Bok, F.A.M.; Hugenholtz, J.; van Hylckama Vlieg, J.E.T. Unraveling Microbial Interactions in Food Fermentations: From Classical to Genomics Approaches. Appl. Environ. Microbiol. 2008, 74, 4997-5007. [CrossRef] [PubMed]

3. Wolfe, B.E.; Dutton, R.J. Fermented Foods as Experimentally Tractable Microbial Ecosystems. Cell 2015, 161, 49-55. [CrossRef]

4. Villarreal-Soto, S.A.; Beaufort, S.; Bouajila, J.; Souchard, J.-P.; Taillandier, P. Understanding Kombucha Tea Fermentation: A Review. J. Food Sci. 2018, 83, 580-588. [CrossRef]

5. Jayabalan, R.; Malbaša, R.V.; Lončar, E.S.; Vitas, J.S.; Sathishkumar, M. A Review on Kombucha Tea-Microbiology, Composition, Fermentation, Beneficial Effects, Toxicity, and Tea Fungus. Compr. Rev. Food Sci. Food Saf. 2014, 13, 538-550. [CrossRef]

6. Dufresne, C.; Farnworth, E. Tea, Kombucha, and health: A review. Food Res. Int. 2000, 33, 409-421. [CrossRef]

7. Lynch, K.M.; Zannini, E.; Wilkinson, S.; Daenen, L.; Arendt, E.K. Physiology of Acetic Acid Bacteria and Their Role in Vinegar and Fermented Beverages. Compr. Rev. Food Sci. Food Saf. 2019, 18, 587-623. [CrossRef]

8. La China, S.; Zanichelli, G.; De Vero, L.; Gullo, M. Oxidative fermentations and exopolysaccharides production by acetic acid bacteria: A mini review. Biotechnol. Lett. 2018, 40, 1289-1302. [CrossRef]

9. Tran, T.; Grandvalet, C.; Verdier, F.; Martin, A.; Alexandre, H.; Tourdot-Maréchal, R. Microbiological and technological parameters impacting the chemical composition and sensory quality of kombucha. Compr. Rev. Food Sci. Food Saf. 2020, 19, 2050-2070. [CrossRef] 
10. Carlier, A.; Pessi, G.; Eberl, L. Microbial Biofilms and Quorum Sensing. In Principles of Plant-Microbe Interactions; Lugtenberg, B., Ed.; Springer International Publishing: Cham, Switzerland, 2015; pp. 45-52. ISBN 978-3-319-08574-6.

11. Flemming, H.-C.; Wingender, J.; Szewzyk, U.; Steinberg, P.; Rice, S.A.; Kjelleberg, S. Biofilms: An emergent form of bacterial life. Nat. Rev. Microbiol. 2016, 14, 563-575. [CrossRef]

12. Gullo, M.; La China, S.; Falcone, P.M.; Giudici, P. Biotechnological production of cellulose by acetic acid bacteria: Current state and perspectives. Appl. Microbiol. Biotechnol. 2018, 102, 6885-6898. [CrossRef]

13. May, A.; Narayanan, S.; Alcock, J.; Varsani, A.; Maley, C.; Aktipis, A. Kombucha: A novel model system for cooperation and conflict in a complex multi-species microbial ecosystem. Peer] 2019, 7, e7565. [CrossRef]

14. Coton, M.; Pawtowski, A.; Taminiau, B.; Burgaud, G.; Deniel, F.; Coulloumme-Labarthe, L.; Fall, A.; Daube, G.; Coton, E. Unraveling microbial ecology of industrial-scale Kombucha fermentations by metabarcoding and culture-based methods. FEMS Microbiol. Ecol. 2017, 93. [CrossRef]

15. Teoh, A.L.; Heard, G.; Cox, J. Yeast ecology of Kombucha fermentation. Int. J. Food Microbiol. 2004, 95, 119-126. [CrossRef]

16. Liu, C.-H.; Hsu, W.-H.; Lee, F.-L.; Liao, C.-C. The isolation and identification of microbes from a fermented tea beverage, Haipao, and their interactions during Haipao fermentation. Food Microbiol. 1996, 13, 407-415. [CrossRef]

17. Wang, S.; Zhang, L.; Qi, L.; Liang, H.; Lin, X.; Li, S.; Yu, C.; Ji, C. Effect of synthetic microbial community on nutraceutical and sensory qualities of kombucha. Int. J. Food Sci. Technol. 2020. [CrossRef]

18. Lawson, C.E.; Harcombe, W.R.; Hatzenpichler, R.; Lindemann, S.R.; Löffler, F.E.; O’Malley, M.A.; García Martín, H.; Pfleger, B.F.; Raskin, L.; Venturelli, O.S.; et al. Common principles and best practices for engineering microbiomes. Nat. Rev. Microbiol. 2019, 17, 725-741. [CrossRef]

19. Green, S.R.; Gray, P.P. A differential procedure for bacteriological studies useful in the fermentation industry. Arch. Biochem. Biophys. 1951, 32, 59-69. [CrossRef]

20. Hall, J.F. Detection of wild yeasts in the brewery. J. Inst. Brew. 1971, 77, 513-516. [CrossRef]

21. Pallmann, C.L.; Brown, J.A.; Olineka, T.L.; Cocolin, L.; Mills, D.A.; Bisson, L.F. Use of WL Medium to Profile Native Flora Fermentations. Am. J. Enol. Vitic. 2001, 52, 198-203.

22. Simonin, S.; Alexandre, H.; Nikolantonaki, M.; Coelho, C.; Tourdot-Maréchal, R. Inoculation of Torulaspora delbrueckii as a bio-protection agent in winemaking. Food Res. Int. 2018. [CrossRef] [PubMed]

23. Salma, M.; Rousseaux, S.; Sequeira-Le Grand, A.; Alexandre, H. Cytofluorometric detection of wine lactic acid bacteria: Application of malolactic fermentation to the monitoring. J. Ind. Microbiol. Biotechnol. 2013, 40, 63-73. [CrossRef] [PubMed]

24. Maoura, N.; Mbaiguinam, M.; Nguyen, H.V.; Gaillardin, C.; Pourquie, J. Identification and typing of the yeast strains isolated from bili bili, a traditional sorghum beer of Chad. Afr. J. Biotechnol. 2005, 4, 646-656. [CrossRef]

25. Esteve-Zarzoso, B. Identification of yeasts by RFLP analysis of the 5.85 rRNA gene and the two ribosomal internal transcribed spacers. Int. J. Syst. Bacteriol. 2019, 49, 329-337. [CrossRef] [PubMed]

26. Wang, Y.; Qian, P.-Y. Conservative Fragments in Bacterial $16 S$ rRNA Genes and Primer Design for $16 S$ Ribosomal DNA Amplicons in Metagenomic Studies. PLoS ONE 2009, 4, e7401. [CrossRef]

27. Stiefel, P.; Schmidt-Emrich, S.; Maniura-Weber, K.; Ren, Q. Critical aspects of using bacterial cell viability assays with the fluorophores SYTO9 and propidium iodide. BMC Microbiol. 2015, 15, 36. [CrossRef]

28. Cvetković, D.; Markov, S.; Djurić, M.; Savić, D.; Velićanski, A. Specific interfacial area as a key variable in scaling-up Kombucha fermentation. J. Food Eng. 2008, 85, 387-392. [CrossRef]

29. OIV. Méthode OIV-MA-AS313-01: Acidité Totale; Recueil International des Méthodes d'Analyse-OIV: Paris, France, 2009.

30. MEBAK 2.6.4.1.1 Ninhydrin Method (Photometric Method, EBC). In MEBAK Wort, Beer, Beer-Based Beverages: Collection of Brewing Analysis Methods of the Mitteleuropäische Brautechnische Analysenkommission (MEBAK); Freising-Weihenstephan: Munich, Germany, 2013.

31. Zou, X.; Zhang, S.; Chen, L.; Hu, J.; Hong, F.F. Determination of live and dead Komagataeibacter xylinus cells and first attempt at precise control of inoculation in nanocellulose production. Microb. Biotechnol. 2020, 13, 458-469. [CrossRef]

32. Millet, V.; Lonvaud-Funel, A. The viable but non-culturable state of wine micro-organisms during storage. Lett. Appl. Microbiol. 2000, 30, 136-141. [CrossRef] 
33. Lee, J.; Schreiner, R.P. Free amino acid profiles from 'Pinot noir' grapes are influenced by vine N-status and sample preparation method. Food Chem. 2010, 119, 484-489. [CrossRef]

34. Aguilar Uscanga, M.G.; Délia, M.-L.; Strehaiano, P. Brettanomyces bruxellensis: Effect of oxygen on growth and acetic acid production. Appl. Microbiol. Biotechnol. 2003, 61, 157-162. [CrossRef] [PubMed]

35. Custer, M. Onderzoekingen over Het Gistgeslacht Brettanomyces. Ph.D. Thesis, University of Delft, Delft, The Netherlands, 1940.

36. Nogueira, A.; le Quéré, J.M.; Drilleau, J.F.; Wosiacki, G. Fermentation Behavior of Apiculate Yeast Hanseniaspora valbyensis in Cider Processing Conditions; International Commission of Agricultural Engineering (CIGR), Institut fur Landtechnik: Bonn, Germany, 2008; p. Ref.20.

37. Özcan, S.; Vallier, L.G.; Flick, J.S.; Carlson, M.; Johnson, M. Expression of the SUC2 Gene of Saccharomyces cerevisiae is Induced by Low Levels of Glucose. Yeast 1997, 13, 127-137. [CrossRef]

38. Meijer, M.M.C.; Boonstra, J.; Verkleij, A.J.; Verrips, C.T. Glucose Repression in Saccharomyces cerevisiae Is Related to the Glucose Concentration Rather Than the Glucose Flux. J. Biol. Chem. 1998, 273, 24102-24107. [CrossRef] [PubMed]

39. Marques, W.L.; Raghavendran, V.; Stambuk, B.U.; Gombert, A.K. Sucrose and Saccharomyces cerevisiae: A relationship most sweet. FEMS Yeast Res. 2016, 16, fov107. [CrossRef] [PubMed]

40. Berthels, N.; Corderootero, R.; Bauer, F.; Thevelein, J.; Pretorius, I. Discrepancy in glucose and fructose utilisation during fermentation by wine yeast strains. FEMS Yeast Res. 2004, 4, 683-689. [CrossRef]

41. Berthels, N.J.; Cordero Otero, R.R.; Bauer, F.F.; Pretorius, I.S.; Thevelein, J.M. Correlation between glucose/fructose discrepancy and hexokinase kinetic properties in different Saccharomyces cerevisiae wine yeast strains. Appl. Microbiol. Biotechnol. 2008, 77, 1083-1091. [CrossRef]

42. Velasco-Bedrán, H.; López-Isunza, F. The unified metabolism of Gluconacetobacter entanii in continuous and batch processes. Process Biochem. 2007, 42, 1180-1190. [CrossRef]

43. Sharma, C.; Bhardwaj, N.K. Biotransformation of fermented black tea into bacterial nanocellulose via symbiotic interplay of microorganisms. Int. J. Biol. Macromol. 2019, 132, 166-177. [CrossRef]

44. De Ley, J. Comparative carbohydrate metabolism and a proposal for a phylogenetic relationship of the acetic acid bacteria. Microbiology 1961, 24, 31-50. [CrossRef]

45. De Ley, J.; Schell, J. Lactate and Pyruvate Catabolism in Acetic Acid Bacteria. J. Gen. Microbiol. 1962, 29, 589-601. [CrossRef]

46. Prust, C.; Hoffmeister, M.; Liesegang, H.; Wiezer, A.; Fricke, W.F.; Ehrenreich, A.; Gottschalk, G.; Deppenmeier, U. Complete genome sequence of the acetic acid bacterium Gluconobacter oxydans. Nat. Biotechnol. 2005, 23, 195-200. [CrossRef] [PubMed]

47. Dong, Y.; Hu, J.; Fan, L.; Chen, Q. RNA-Seq-based transcriptomic and metabolomic analysis reveal stress responses and programmed cell death induced by acetic acid in Saccharomyces cerevisiae. Sci. Rep. 2017, 7. [CrossRef] [PubMed]

48. Drysdale, G.S.; Fleet, G.H. The effect of acetic acid bacteria upon the growth and metabolism of yeasts during the fermentation of grape juice. J. Appl. Bacteriol. 1989, 67, 471-481. [CrossRef]

49. Chen, C.; Liu, B.Y. Changes in major components of tea fungus metabolites during prolonged fermentation. J. Appl. Microbiol. 2000, 89, 834-839. [CrossRef]

50. Goh, W.N.; Rosma, A.; Kaur, B.; Fazilah, A.; Karim, A.A.; Bhat, R. Fermentation of black tea broth (Kombucha): I. Effects of sucrose concentration and fermentation time on the yield of microbial cellulose. Int. Food Res. J. 2012, 19, 109-117.

51. Blanc, P.J. Characterization of the tea fungus metabolites. Biotechnol. Lett. 1996, 18, 139-142. [CrossRef]

52. Sievers, M.; Lanini, C.; Weber, A.; Schuler-Schmid, U.; Teuber, M. Microbiology and fermentation balance in a kombucha beverage obtained from a tea fungus fermentation. Syst. Appl. Microbiol. 1995, 18, 590-594. [CrossRef]

53. Andjelković, U.; Milutinović-Nikolić, A.; Jović-Jovičić, N.; Banković, P.; Bajt, T.; Mojović, Z.; Vujčić, Z.; Jovanović, D. Efficient stabilization of Saccharomyces cerevisiae external invertase by immobilisation on modified beidellite nanoclays. Food Chem. 2015, 168, 262-269. [CrossRef]

54. Beteta, P.; Gascon, S. Localization of invertase in yeast vacuoles. FEBS Lett. 1971, 13, 297-300. [CrossRef]

55. Margetić, A.; Vujčić, Z. Comparative study of stability of soluble and cell wall invertase from Saccharomyces cerevisiae. Prep. Biochem. Biotechnol. 2017, 47, 305-311. [CrossRef] 
56. Neumann, N.P.; Lampen, J.O. Glycoprotein structure of yeast invertase. Biochemistry 1969, 8, 3552-3556. [CrossRef] [PubMed]

57. Blondin, B.; Ratomahenina, R. Purification and Properties of the $\beta$-Glucosidase of a Yeast Capable of Fermenting Cellobiose to Ethanol: Dekkera intermedia Van der Walt. Eur. J. Microbiol. Biotechnol. 1983, 17, 1-6. [CrossRef]

58. Conterno, L.; Joseph, C.M.L.; Arvik, T.J.; Henick-Kling, T.; Bisson, L.F. Genetic and Physiological Characterization of Brettanomyces bruxellensis Strains Isolated from Wines. Am. J. Enol. Vitic. 2006, 139-147.

59. Fia, G.; Giovani, G.; Rosi, I. Study of beta-glucosidase production by wine-related yeasts during alcoholic fermentation. A new rapid fluorimetric method to determine enzymatic activity. J. Appl. Microbiol. 2005, 99, 509-517. [CrossRef] [PubMed]

60. Roach, M.J.; Borneman, A.R. New genome assemblies reveal patterns of domestication and adaptation across Brettanomyces (Dekkera) species. BMC Genom. 2020, 21, 14. [CrossRef]

61. Steenwyk, J.L.; Opulente, D.A.; Kominek, J.; Shen, X.-X.; Zhou, X.; Labella, A.L.; Bradley, N.P.; Eichman, B.F.; Čadež, N.; Libkind, D.; et al. Extensive loss of cell-cycle and DNA repair genes in an ancient lineage of bipolar budding yeasts. PLoS Biol. 2019, 17, e3000255. [CrossRef]

62. Alexandre, H.; Heintz, D.; Chassagne, D.; Guilloux-Benatier, M.; Charpentier, C.; Feuillat, M. Protease A activity and nitrogen fractions released during alcoholic fermentation and autolysis in enological conditions. J. Ind. Microbiol. Biotechnol. 2001, 26, 235-240. [CrossRef]

63. Guilloux-Benatier, M.; Chassagne, D.; Alexandre, H.; Charpentier, C.; Feuillat, M. Influence of yeast autolysis after alcoholic fermentation on the development of Brettanomyces/Dekkera in wine. OENO One 2001, 35, 157. [CrossRef]

64. Charoenchai, C.; Fleet, G.H.; Henschke, P.A.; Todd, B.E.N. Screening of non-Saccharomyces wine yeasts for the presence of extracellular hydrolytic enzymes. Aust. J. Grape Wine Res. 1997, 3, 2-8. [CrossRef]

65. Younes, B.; Cilindre, C.; Villaume, S.; Parmentier, M.; Jeandet, P.; Vasserot, Y. Evidence for an Extracellular Acid Proteolytic Activity Secreted by Living Cells of Saccharomyces cerevisiae PIR1: Impact on Grape Proteins. J. Agric. Food Chem. 2011, 59, 6239-6246. [CrossRef] [PubMed]

66. Guilloux-Benatier, M.; Chassagne, D. Comparison of Components Released by Fermented or Active Dried Yeasts after Aging on Lees in a Model Wine. J. Agric. Food Chem. 2003, 51, 746-751. [CrossRef]

67. Torres, A.P.; Oliveira, F.A.R.; Silva, C.L.M.; Fortuna, S.P. The influence of $\mathrm{pH}$ on the kinetics of acid hydrolysis of sucrose. J. Food Process Eng. 1994, 17, 191-208. [CrossRef]

68. Jakob, F.; Quintero, Y.; Musacchio, A.; Estrada-de los Santos, P.; Hernández, L.; Vogel, R.F. Acetic acid bacteria encode two levansucrase types of different ecological relationship. Environ. Microbiol. 2019, 21, 4151-4165. [CrossRef]

69. Balasubramaniam, K.; Kannangara, P.N. Sucrose Phosphorylase and Invertase Activities in Bacteria. J. Natl. Sci. Found. Sri Lanka 1982, 10, 169-180. [CrossRef]

70. Albergaria, H.; Francisco, D.; Gori, K.; Arneborg, N.; Gírio, F. Saccharomyces cerevisiae CCMI 885 secretes peptides that inhibit the growth of some non-Saccharomyces wine-related strains. Appl. Microbiol. Biotechnol. 2010, 86, 965-972. [CrossRef]

71. Branco, P.; Viana, T.; Albergaria, H.; Arneborg, N. Antimicrobial peptides (AMPs) produced by Saccharomyces cerevisiae induce alterations in the intracellular $\mathrm{pH}$, membrane permeability and culturability of Hanseniaspora guilliermondii cells. Int. J. Food Microbiol. 2015, 205, 112-118. [CrossRef] [PubMed]

72. Pereznevado, F.; Albergaria, H.; Hogg, T.; Girio, F. Cellular death of two non-Saccharomyces wine-related yeasts during mixed fermentations with Saccharomyces cerevisiae. Int. J. Food Microbiol. 2006, 108, 336-345. [CrossRef] [PubMed]

73. Wang, C.; Mas, A.; Esteve-Zarzoso, B. The Interaction between Saccharomyces cerevisiae and Non-Saccharomyces Yeast during Alcoholic Fermentation Is Species and Strain Specific. Front. Microbiol. 2016, 7, Article 502. [CrossRef] [PubMed]

74. Gobert, A.; Tourdot-Maréchal, R.; Morge, C.; Sparrow, C.; Liu, Y.; Quintanilla-Casas, B.; Vichi, S.; Alexandre, H. Non-Saccharomyces Yeasts Nitrogen Source Preferences: Impact on Sequential Fermentation and Wine Volatile Compounds Profile. Front. Microbiol. 2017, 8. [CrossRef] [PubMed]

75. Renault, P.E.; Albertin, W.; Bely, M. An innovative tool reveals interaction mechanisms among yeast populations under oenological conditions. Appl. Microbiol. Biotechnol. 2013, 97, 4105-4119. [CrossRef] 
76. Soares, E.V. Flocculation in Saccharomyces cerevisiae: A review: Yeast flocculation: A review. J. Appl. Microbiol. 2011, 110, 1-18. [CrossRef]

77. Greig, D.; Travisano, M. The Prisoner's Dilemma and polymorphism in yeast SUC genes. Proc. R. Soc. Lond. B Biol. Sci. 2004, 271. [CrossRef]

78. Celiker, H.; Gore, J. Competition between species can stabilize public-goods cooperation within a species. Mol. Syst. Biol. 2012, 8, 621. [CrossRef] [PubMed]

79. Jayabalan, R.; Marimuthu, S.; Swaminathan, K. Changes in content of organic acids and tea polyphenols during kombucha tea fermentation. Food Chem. 2007, 102, 392-398. [CrossRef]

80. Harrington, K.I.; Sanchez, A. Eco-evolutionary dynamics of complex social strategies in microbial communities. Commun. Integr. Biol. 2014, 7, e28230. [CrossRef] [PubMed]

81. Sanchez, A.; Gore, J. Feedback between Population and Evolutionary Dynamics Determines the Fate of Social Microbial Populations. PLoS Biol. 2013, 11, e1001547. [CrossRef] [PubMed]

82. Langenberg, A.-K.; Bink, F.J.; Wolff, L.; Walter, S.; von Wallbrunn, C.; Grossmann, M.; Heinisch, J.J.; Schmitz, H.-P. Glycolytic Functions Are Conserved in the Genome of the Wine Yeast Hanseniaspora uvarum, and Pyruvate Kinase Limits Its Capacity for Alcoholic Fermentation. Appl. Environ. Microbiol. 2017, 83. [CrossRef]

83. Leistner, L. Basic aspects of food preservation by hurdle technology. Int. J. Food Microbiol. 2000, 55, 181-186. [CrossRef]

(C) 2020 by the authors. Licensee MDPI, Basel, Switzerland. This article is an open access article distributed under the terms and conditions of the Creative Commons Attribution (CC BY) license (http://creativecommons.org/licenses/by/4.0/). 